\title{
Determinantes do consumo de frutas, legumes e verduras em adultos residentes no município de São Paulo.
}

Iramaia Campos Ribeiro Figueiredo

Dissertação apresentada ao
Programa de Pós-Graduação em
Saúde Pública da Faculdade de
Saúde Pública para obtenção do
título de Mestre em Saúde Pública

Área de concentração: Nutrição

Orientadora: Prof $^{\mathrm{a}} \quad \mathrm{Dr}^{\mathrm{a}} \quad$ Patrícia

Constante Jaime

São Paulo

$-2006-$ 
É expressamente proibida a comercialização deste documento tanto na sua forma impressa como eletrônica. Sua reprodução total ou parcial é permitida exclusivamente para fins acadêmicos e científicos, desde que na reprodução figure a identificação do autor, título, instituição e ano da dissertação. 
Ao meu marido,

Eduardo Camargo Figueiredo. Sem você, nada disso seria possível. 


\section{AGRADECIMENTOS:}

À Prof ${ }^{a}$ Dr $^{\mathrm{a}}$ Patrícia Constante Jaime, minha orientadora, por ter me acolhido, por sua dedicação, por acreditar e incentivar sempre.

À Prof ${ }^{a}$ Dr $^{a}$ Erly Catarina de Moura, pelos ensinamentos, pelo carinho e pela amizade. Sem o seu incentivo este trabalho não seria possível.

À Tereza Etsuko Costa Rosa, pela atenção, pela receptividade e ensinamentos transmitidos com tanta paciência.

À Prof ${ }^{\mathrm{a}} \mathrm{Dr}^{\mathrm{a}}$ Maria Helena D’Aquino Benício, por seus aportes a este trabalho.

Ao Prof.. Dr.. Carlos Augusto Monteiro, pela confiança em mim depositada.

Aos membros da banca examinadora, pelos aportes a este trabalho.

Ao CNPq, pela bolsa de estudos concedida.

Aos funcionários da Faculdade de Saúde Pública, especialmente os do departamento de Nutrição. 
Aos amigos Daniel Bandoni, Rafael Claro, Bettina Brasil, Renata Siqueira, Yara Queiroz e Flávia Mori pelo companheirismo e bons momentos passados juntos nesses anos de mestrado.

Aos amigos distantes, porém sempre presentes, Alex Silva, Ilma Costa e Silvia Mello.

Aos meus pais, Augusto Ribeiro e Benê, que despertaram em mim o interesse pelos estudos e sempre me apoiaram nesse sentido.

Ao meu querido marido, Eduardo Camargo Figueiredo, pelo carinho, pelo companheirismo, por acreditar em mim, por me mostrar a cada dia que a vida pode ser melhor.

Muito obrigada! 


\section{RESUMO}

Figueiredo ICR. Determinantes do Consumo de Frutas, Legumes e Verduras em Adultos Residentes no Município de São Paulo. [Dissertação de Mestrado]. São Paulo: Faculdade de Saúde Pública - USP; 2006.

Introdução: A incidência de doenças crônicas não trans missíveis (DCNT) vem aumentando em todo o mundo. Estudos comprovam que o consumo de frutas, legumes e verduras (FLV) reduzem a incidência de DCNT na população Objetivo: Avaliar os determinantes do consumo de FLV em adultos residentes no município de São Paulo Metodologia: É um estudo transversal, abrangendo 1267 mulheres e 855 homens, com idade igual ou superior a 18 anos. A análise de regressão linear foi baseada no modelo hierárquico de fatores associados ao consumo de FLV. As variáveis foram agrupadas em categorias hierárquicas, abrangendo dos fatores distais aos proximais. Essas categorias foram, nessa ordem, sócio-demográfica, comportamental e de consumo alimentar. Resultados: Para ambos os sexos, verificou-se que as seguintes variáveis estavam diretamente associadas ao consumo de FLV: idade e anos de estudo, na categoria sóciodemográfica; prática de atividade física no lazer e ter feito dieta no último ano, na categoria comportamental e consumo de peixe na categoria de consumo alimentar. A densidade domiciliar mostrourse inversamente associada ao consumo de FLV em ambos os sexos. Somente para as mulheres ser ou já ter sido casada foi diretamente associado ao consumo de FLV e ser fumante mostrourse inversamente associado. O consumo de alimentos que indicam um padrão de consumo não saudável como açúcares e carne vermelha com gordura mostrou-se inversamente associado ao consumo de FLV em ambos os sexos. Conclusão: O consumo de FLV e seus determinantes são diferentes para homens e mulheres, sendo a maior freqüência de consumo ocorre no sexo feminino.

Palavras-chave: inquéritos sobre dieta, frutas, legumes e verduras, fatores determinantes, modelos estatísticos. 


\section{ABSTRACT}

Figueiredo ICR. Determinants of Fruit and vegetable intake in adults living in São Paulo City. [dissertation] - São Paulo (BR): Faculdade de Saúde Pública da Universidade de São Paulo; 2006.

The burden of noncommunicable diseases (NCD) increases in the whole world. Studies prove that consumption do fruits and vegetables (FV) reduce the incidence of NTCD in the population. The present study aims to evaluate by telephones interviews the determinants of Fruit and vegetable's intake in adults living in São Paulo City. This is a cross-sectional study, ranging over 1267 women and 855 men, aged 18 years old or more. Multiple linear regression analysis was based on a hierarchical model of factors associated with FV intake. The variables were grouped into a hierarchy of categories, ranging from distal determinants to proximate ones. These categories included, in this order, socio-demographic, behavioral and food consumption. For both gender, we found that the following variables were directly associated with FV intake: age and years of study, in the socio-demographic category, physical activity in leisure time and have been on a diet in the last year, in the behavioral category and fish consumption in the nutritional category. The domiciliary density was inversely associated with FLV consumption for both genders. Only for women marital status was directly associated with FV intake and tobacco use were inversely associated. The dietary intake of food that indicates an unhealthy diet, like sugar and read meat with fat were inversely associated with FV intake for both gender. Consumption of FV and their determinants are different for man and women and the major consumption occurs with women.

Keywords: diet surveys, fruit, vegetables, determinants factors, statistical models. 


\section{SUMÁRIO}

1. INTRODUÇÃO_______________________________ 11

2. OBJETIVOS ___________________________________________________ 18

2.1 GERAL _________________________________________ 18

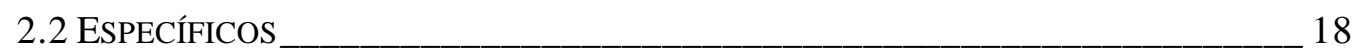

3. METODOLOGIA_____________________________ 19

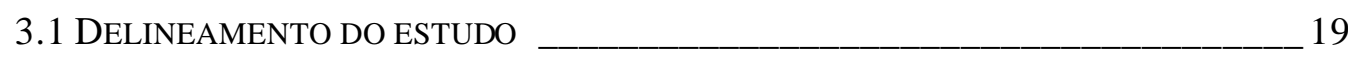

3.2 PoPUlaÇÃO DE ESTUdO E AMOSTRAGEM_______________________________ 19

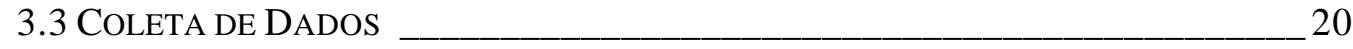

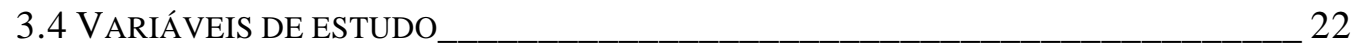

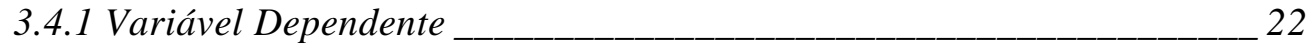

3.4.2 Variáveis Independentes __________________________________ 23

3.5 ELABORAÇÃO DO BANCO DE DADOS_____________ 27

3.6 ANÁLISE DOS DADOS ___________________________ 27

3.7 ASPECTOS ÉTICOS _________________ 31

4. RESULTADOS ______________________________ 32

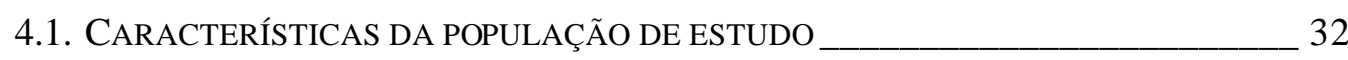

4.2. RELAÇÃO DAS VARIÁVEIS INDEPENDENTES COM OCONSUMO DE FLV _____ 38

4.3 ANÁLISE DE REGRESSÃO LINEAR MÚLTIPLA HIERARQUIZADA DOS FATORES RELACIONADOS AO CONS UMO DE FLV. ________________________ 43

5. DISCUSSÃO _____________________________________ 51

6. CONCLUSÃO________________________________ 59

REFERÊNCIAS BIBLIOGRÁFICAS_______________________ 60

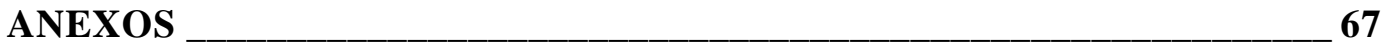

ANEXO 1 _____________________________________ 67

ANEXO2 ________________________ 68

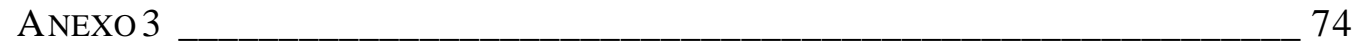

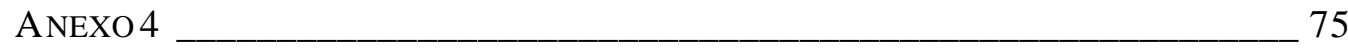

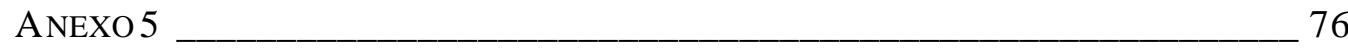




\section{Lista de figuras e tabelas}

Figura 1

Marco teórico para análise do consumo de frutas, legumes e verduras em adultos residentes no município de São Paulo.

Figura 2

Fatores associados ao consumo de frutas, legumes e verduras em adultos do sexo feminino residentes no município de São Paulo.

Figura 3

Fatores associados ao consumo de frutas, legumes e verduras em adultos do sexo masculino residentes no município de São Paulo.

Tabela 1

Distribuição numérica e percentual da população estudada segundo sexo e as características sócio-demográficas. São Paulo-Capital, 2003.

Tabela 2

Distribuição numérica e percentual da população estudada segundo sexo e as variáveis comportamentais. São Paulo-Capital, 2003.

Tabela 3

Distribuição numérica e percentual da população estudada segundo sexo e as variáveis dicotômicas de consumo de frutas, legumes e verduras. São Paulo - Capital, 2003.

Tabela 4

Distribuição numérica e percentual da população estudada segundo sexo e as variáveis de consumo alimentar. São Paulo-Capital, 2003.

Tabela 5

Medidas de tendência central e de dispersão do consumo de FLV e variáveis sócio-demográficas, consumo de álcool e consumo de alimentos para o sexo feminino. São Paulo-Capital, 2003. 
Medidas de tendência central e de dispersão do consumo de FLV e variáveis sócio-demográficas, consumo de álcool e consumo de alimentos para o sexo masculino. São Paulo - Capital, 2003.

\section{Tabela 7}

Correlação das variáveis independentes quantitativas com o escore da freqüência de consumo de FLV para o sexo feminino. São Paulo - Capital, 2003.

Tabela 8

Correlação das variáveis independentes quantitativas com o escore da freqüência de consumo de FLV para o sexo masculino. São Paulo - Capital, 2003.

Tabela 9

Diferenças de médias e desvios padrão do consumo de FLV segundo as variáveis sócio-demográficas e comportamentais para o sexo feminino. São Paulo - Capital, 2003.

Tabela 10

Diferenças de médias e desvios padrão do consumo de FLV segundo as variáveis sócio-demográficas e comportamentais para o sexo masculino. São Paulo - Capital, 2003.

Tabela 11

42

Diferenças de médias e desvios padrão do consumo de FLV segundo outras variáveis de consumo de alimentos para o sexo feminino. São Paulo Capital, 2003.

Tabela 12

Diferenças de médias e desvios padrão do consumo de FLV segundo outras variáveis de consumo de alimentos para o sexo masculino. São Paulo Capital, 2003.

Tabela 13

Fatores associados ao consumo de FLV identificados mediante análise de regressão linear hierarquizada para o sexo feminino. São Paulo - Capital, 2003. 
Fatores associados ao consumo de FLV identificados mediante análise de regressão linear hierarquizada para o sexo masculino. São Paulo - Capital, 2003. 


\section{INTRODUÇÃO}

A incidência de doenças crônicas vem aumentando em todo o mundo. Em 2001, as doenças crônicas contribuíram com aproximadamente $60 \%$ do total de 56,5 milhões de mortes no mundo e aproximadamente $46 \%$ da carga total de doenças. Estima-se que em 2020 haverá um aumento em $57 \%$ de mortes em decorrência destas doenças (WHO, 2003).

Quase metade das mortes por doenças crônicas é atribuída a doenças cardiovasculares. Obesidade e diabetes também mostram tendências preocupantes, não só porque afetam grande parte da população, mas também porque começaram a atingir as pessoas mais precocemente (WHO, 2003).

Doenças crônicas não transmissíveis (DCNTs), não-infecciosas ou crônico-degenerativas são terminologias usadas para definir grupos de enfermidades que se caracterizam por apresentar, de uma forma geral: longo período de latência; tempo de evolução prolongado, interação entre fatores etiológicos conhecidos e desconhecidos. Apresentam também multiplicidade de fatores de risco complexos; longo curso assintomático; manifestações clínicas com períodos de remissão e exacerbação; curso clínico em geral lento, prolongado e permanente; lesões irreversíveis e complicações que evoluem para graus variáveis de gravidade, incapacidade ou óbito (LESSA, 1998).

O problema das DCNTs está longe de ser limitado às regiões desenvolvidas do mundo. Ao contrário do que se acreditava, os países em 
desenvolvimento estão sofrendo cada vez mais com os altos índices de problemas em saúde pública relacionados às doenças crônicas (WHO, 2002).

A carga total de DCNTs não está igualmente distribuída entre as diferentes classes sócio-econômicas. Em adultos de baixo nível sócioeconômico encontram-se as maiores taxas de morbidade e de mortalidade provenientes de doenças crônicas (GISKES, 2002).

Estudos comprovam que as alterações na dieta têm fortes efeitos, positivos e negativos, na saúde durante toda a vida. O mais importante é que as modificações dietéticas podem não somente influenciar o estado de saúde presente, como podem também determinar se um indivíduo irá desenvolver ou não alguma doença como câncer, doenças cardiovasculares e diabetes, mais tarde em sua vida (WHO, 2003).

Há um grande interesse na associação entre consumo de frutas, legumes e verduras (FLV) e a saúde humana. Devido ao estresse oxidativo ter um papel significativo no processo da maioria das doenças no envelhecimento, os prováveis benefícios das frutas, legumes e verduras são atribuídos à sua potencial capacidade antioxidante.

HYSON (2002) aponta que o efeito protetor do consumo de frutas, legumes e verduras pode se estender além da capacidade antioxidante. $O$ consumo desses alimentos pode diminuir os riscos de morte relacionados a doenças coronarianas e acidente vascular cerebral por meio da modificação da atividade plaquetária, concentração de homocisteína, pressão sangüínea, 
substituição de ácidos graxos na dieta, bem como a redução da ingestão de gordura saturada (STEFFEN e col., 2003).

Além disso, o consumo elevado de FLV reduz o risco de câncer (JOHN e col., 2002). Dados provenientes de estudos epidemiológicos têm indicado que dietas ricas em FLV reduzem o risco de câncer no aparelho digestivo e podem estar associadas com o risco diminuído de outros tipos de câncer, incluindo o de mama (GANDINI e col., 2000). O consumo de hortaliças pode reduzir o risco de câncer de mama por inúmeros mecanismos, especialmente por vegetais que são fontes de carotenóides, vitaminas $A, E$ e $C$, minerais como selênio, e componentes como isoflavonas e ligninas. Os glucosinatos, encontrados em vegetais crucíferos, tais como couve e repolho, podem ser importantes anticarcinogênicos (AMBROSONE e col., 2004).

As metas de ingestão de nutrientes representam a média de ingestão que se julga necessária para manter a saúde da população. A meta de ingestão de frutas, legumes e verduras preconizada pela Organização Mundial da Saúde (OMS) é de $\geq 400 \mathrm{~g} /$ dia (WHO, 2003).

No entanto, em diversos estudos realizados, a ingestão de FLV está abaixo do recomendado. Em estudo realizado por STEFFEN e col. (2003) nos Estados Unidos, verificou-se que a média de ingestão desses alimentos entre adultos norte-americanos era de 3,4 porções ao dia, sendo que somente $23 \%$ dos adultos norte-americanos consumiam a quantidade recomendada. Na Irlanda, o consumo médio de frutas, legumes e verduras 
foi de 140 g/dia (O'BRIEN e col., 2003). No Reino Unido, apenas 40\% da população atinge a meta preconizada pela OMS (JOHN e col., 2002).

Diversos estudos demonstram que o consumo de frutas, legumes e verduras também é influenciado por fatores sócio-demográficos, como idade, sexo, raça, educação, renda e tabagismo. Em estudo realizado nos Estados Unidos, a ingestão de FLV era maior entre aqueles que possuíam maior escolaridade, maior renda e eram não fumantes (SUBAR e col., 1995). Na Austrália, TURRELL e col. (2003) verificaram que a renda familiar é o melhor indicador da escolha alimentar; principalmente entre as famílias de menor renda. A correlação inversa entre pouca escolaridade e baixo nível social e menor consumo de frutas, hortaliças foi confirmada nos estudos de O'BRIEN, na Irlanda; GISKES, na Austrália, e SUBAR, nos Estados Unidos.

A ingestão destes alimentos é maior entre mulheres do que entre homens. Em estudo realizado com adultos no Reino Unido, verificou-se que as mulheres consomem significativamente mais frutas, legumes e verduras do que os homens, com o total de 3,5 porções ao dia comparado, com 2,5 porções para os homens (BAKER \& WARDLE, 2003).

Outro fator determinante do consumo de frutas, legumes e verduras é a idade. SUBAR e col. (1995) verificaram que mulheres têm uma maior ingestão de FLV do que os homens em todas as idades e esta diferença aumenta com a idade para brancos e hispânicos. Adolescentes consomem menos hortaliças e em menor variedade do que adultos. A associação estatisticamente significativa entre idade e consumo de frutas, legumes e 
verduras também foi verificada em outros estudos (THOMPSON e col., 1999; McCLELLAND e col., 1998).

No Brasil, as estimativas existentes sobre o consumo de frutas, legumes e verduras foram obtidas por meio de Pesquisas de Orçamentos Familiares (POFs), realizadas entre os anos de 1962 a 1996, que mostram um declínio na compra familiar de frutas e de sucos naturais, e um insuficiente consumo de hortaliças, ficando abaixo da recomendação da OMS (MONDINI \& MONTEIRO,1994; MONTEIRO e col., 2000).

LEVY-COSTA e col. (2005) em estudo sobre a distribuição e evolução da disponibilidade domiciliar de alimentos no Brasil entre os anos de 1974 e 2003 verificaram que frutas, legumes e verduras correspondem a apenas $2,3 \%$ das calorias totais da dieta, o que corresponde a aproximadamente um terço do recomendado (400 gramas diárias ou cerca de $6-7 \%$ das calorias totais de uma dieta de $2.300 \mathrm{Kcal})$.

O único estudo realizado com abrangência nacional no Brasil que coletou informações sobre o consumo de frutas, verduras e legumes foi a Pesquisa Mundial de Saúde - PMS, realizada pela Organização Mundial de Saúde em parceria com a Fundação Oswaldo Cruz em 2003. Com base nas informações coletadas nessa pesquisa, JAIME e MONTEIRO (2005) estimaram a freqüência e a distribuição do consumo de FLV na população brasileira, verificando que menos da metade dos indivíduos no Brasil consome frutas diariamente e menos de um terço da população relata o consumo diário de hortaliças. 
A investigação direta do consumo alimentar a partir da aplicação de inquéritos dietéticos constitui a forma ideal para se caracterizar os padrões dietéticos vigentes de uma dada população e sua evolução ao longo do tempo. Entretanto, tal método exige o estudo de grandes amostras por períodos relativamente longos de tempo, condição que encarece os inquéritos dietéticos e os torna pouco factíveis.

Uma melhor alternativa, na ausência de inquéritos dietéticos, é um sistema de monitoramento por telefone.

Em países desenvolvidos, sistemas de monitoramento por telefone das condições de saúde vêm sendo utilizados com sucesso em populações que dispõem de serviços de telefonia com ampla cobertura residencial (CDC, 2003). Entre as principais vantagens desse sistema estão o baixo custo e a possibilidade de sua implantação em localidades onde é improvável que existam os recursos humanos e materiais necessários para se conduzir inquéritos probabilísticos domiciliares (REMINGTON e col., 1988).

As limitações do sistema de monitoramento por telefone são: primeiro, as de excluir pessoas que vivem em instituições como asilos, casas de repouso, casas geriátricas; segundo, os dados coletados referem-se a informações fornecidas pelos entrevistadores e podem estar sujeitas aos vieses de memória; terceiro, obviamente, exclui pessoas que não possuem telefone fixo, podendo excluir pessoas de baixa renda ou que possuam somente o telefone celular (CDC, 2003). 
Estudos de confiabilidade realizados em países desenvolvidos têm indicado alta concordância entre entrevistas telefônicas e entrevistas domiciliares (REMINGTON e col., 1988). Em estudo realizado para avaliar o consumo de frutas, legumes e verduras em diversas regiões, por meio de entrevistas telefônicas, não foram encontradas diferenças estatisticamente significantes entre o monitoramento telefônico e outros métodos de inquérito alimentar, como: recordatório alimentar, registro alimentar e questionário de freqüência alimentar (SERDULA e col., 1993).

Visto que as DCNTs constituem um importante problema de saúde pública e que a dieta é um dos seus principais determinantes, o presente estudo propõe-se a avaliar os determinantes de consumo de frutas, legumes e verduras dentro de uma proposta de Sistema Municipal de Monitoramento de Fatores de Risco Nutricionais para Doenças Crônicas Não Transmissíveis. 


\section{OBJETIVOS}

\subsection{Geral}

Avaliar os determinantes do consumo de frutas, legumes e verduras em adultos residentes no Município de São Paulo.

\subsection{Específicos}

$\rightarrow$ Identificar e descrever o consumo de frutas, legumes e verduras;

$\rightarrow$ Identificar e avaliar a relação entre o consumo de frutas, legumes e verduras e variáveis sócio-econômicas e demográficas;

$\rightarrow$ Identificar e avaliar a relação entre o consumo de frutas, legumes e verduras e variáveis comportamentais;

$\rightarrow$ Identificar e avaliar a relação entre o consumo de frutas, legumes e verduras e outras variáveis de consumo, marcadoras de um padrão de consumo alimentar saudável ou não saudável. 


\section{METODOLOGIA}

Este estudo apresenta dados primários, coletados no ano de 2003, dentro de um amplo projeto intitulado "Sistema municipal de monitoramento de fatores de risco nutricionais para doenças não transmissíveis a partir de entrevistas telefônicas: delineamento, implantação experimental e estudo de confiabilidade e validade", convênio do Ministério da Saúde com o NUPENS (Núcleo de Pesquisas Epidemiológicas em Nutrição e Saúde) da Faculdade de Saúde Pública da Universidade de São Paulo.

A coleta de dados ocorreu no período de setembro a dezembro de 2003, sendo parte das atividades desenvolvidas pela autora, como bolsista de apoio técnico do Conselho Nacional de Desenvolvimento Tecnológico e Científico (CNPq - processo 370854/2003-9) no referido projeto.

\subsection{Delineamento do estudo}

O delineamento desta pesquisa corresponde a um estudo observacional, transversal, com base populacional, realizado por meio de inquérito epidemiológico.

\subsection{População de estudo e amostragem}

A população de estudo correspondeu à população de homens e mulheres com 18 anos ou mais anos de idade que em 2003 residiam em 
domicílios do município de São Paulo, servidos pelo sistema de telefonia fixa.

O plano amostral foi delineado a partir do cadastro de 2003 de linhas telefônicas residenciais do município de São Paulo. A partir deste cadastro, foram sorteados 3150 números, esperando obter um total de 2000 entrevistas completas. Todas as linhas sorteadas foram chamadas em horários e dias variados, incluindo fins de semana. Foram consideradas não elegíveis $20 \%$ das linhas sorteadas, pois se tratava de estabelecimentos comerciais, números fora de serviço, linhas não existentes e números sem atendimento após um mínimo de dez chamadas. As demais linhas $(n=2505)$ foram consideradas elegíveis, incluindo-se números sistematicamente ocupados e números correspondentes a fax ou secretária eletrônica. Houve recusa do sistema de monitoramento em $6,3 \%$ dos números elegíveis ( $n=157$ ) e os números ocupados, fax e secretária eletrônica representaram $1,4 \%$ dos números elegíveis $(n=37)$. Assim, o sorteio do indivíduo a ser entrevistado pôde ser realizado em 2311 (92,3\%) das 2505 linhas elegíveis (MONTEIRO e col., 2005).

\subsection{Coleta de Dados}

Para cada número havia uma chamada inicial, na qual confirma-se se o número era residencial. Após a confirmação, havia o esclarecimento do propósito da pesquisa e o morador era convidado a participar. Após seu consentimento, solicitava-se informar o número total de moradores da residência e quantos deles eram adultos. A pessoa a ser entrevistada era 
escolhida dentre os adultos por sorteio aleatório. Caso fosse sorteado um adulto incapaz de se comunicar por telefone, procedia-se novo sorteio. Todas estas informações eram anotadas em formulário próprio (Anexo 1).

A entrevista consistia em um questionário (Anexo 2) contendo 98 questões. Para que as entrevistas fossem realizadas de maneira mais rápida e segura, foi desenvolvido um software especialmente para a realização deste projeto, criando um questionário eletrônico. Nele, as questões eram apresentadas ao operador na forma de janelas, aparecendo uma por vez. Assim que a resposta era assinalada pelo operador, a pergunta seguinte aparecia automaticamente, bem como algumas eram omitidas de acordo com cada caso, minimizando possíveis erros na aplicação do questionário.

As entrevistas telefônicas duraram em média 5 minutos, sendo realizadas em sua grande maioria por operadores de telemarketing previamente treinados e supervisionados constantemente. Os operadores utilizavam headphones, possibilitando que suas mãos ficassem livres para digitar as respostas no teclado do computador.

Cada entrevista realizada com o auxílio do software gerava automaticamente um novo registro em uma base de dados no formato DBase, eliminando a etapa de digitação dos dados. 


\subsection{Variáveis de estudo}

\subsubsection{Variável Dependente}

As variáveis de desfecho deste estudo são aquelas relacionadas à freqüência (dias na semana) do consumo de frutas, legumes e verduras Questões 36, 38 e 42 do questionário (Anexo 2).

Seguindo-se metodologia proposta por FORNÉS (1998), atribuiu-se um peso $\left(S_{f}\right)$ para cada categoria de freqüência semanal de consumo de frutas, legumes e verduras como a seguir:

$S_{1}=0,00$ (peso para alimentos nunca consumidos)

$S_{2}=0,05$ (peso para alimentos quase nunca consumidos)

$S_{3}=0,20$ (peso para alimentos consumidos de 1 a 2 dias por semana)

$S_{4}=0,46$ (peso para alimentos consumidos de 3 a 4 dias por semana)

$S_{5}=0,73$ (peso para alimentos consumidos de 5 a 6 dias por semana)

$S_{6}=1,00$ (peso para alimentos consumidos todos os dias da semana)

A partir da soma desses pesos, criourse um escore de consumo de frutas, legumes e verduras que variava de zero a três. 


\subsubsection{Variáveis Independentes}

\section{Sócio-demográficas:}

- Sexo: variável categórica dicotômica (feminino, masculino).

- Idade: variável quantitativa contínua.

- Raça auto-referida pelo entrevistado (branca, negra, parda ou morena e amarela): variável categórica dicotômica (branco, não branco).

- Escolaridade: variável quantitativa contínua.

- Densidade domiciliar (obtida por meio da razão do número de moradores pelo número de cômodos do domicílio): variável quantitativa contínua.

- Estado civil informado pelo entrevistado como casado, solteiro, viúvo ou separado: variável categórica dicotômica (solteiro, não solteiro).

- Realização de trabalho remunerado: variável categórica dicotômica (sim, não).

\section{Comportamentais:}

- Tabagismo informado pelo entrevistado como fumante, não-fumante, ex-fumante: variável categórica dicotômica (sim, não).

- Prática de exercício físico no lazer: variável categórica dicotômica (sim, não).

- Hábito de realizar refeições fora de casa ("come fora"): variável categórica dicotômica (sim, não). Esta variável foi obtida no questionário telefônico por meio de categorias de freqüência, sendo 
que as categorias "todos os dias da semana" e "5 a 6 dias na semana" receberam o número 1(um), caracterizando sim; e as demais categorias receberam o número 0 (zero), caracterizando não.

- Hábito de trocar refeições por lanches ("troca comida por lanche"): variável categórica dicotômica (sim, não) Esta variável foi obtida no questionário telefônico por meio de categorias de freqüência, sendo que as categorias "todos os dias da semana" e "5 a 6 dias na semana" receberam o número 1(um), caracterizando sim; e as demais categorias receberam o número 0 (zero), caracterizando não.

- Realizou dieta no último ano ("faz dieta"): variável categórica dicotômica (sim, não).

Nas atividades físicas de lazer foram avaliados o tipo de atividade, a freqüência semanal, a duração diária em minutos e o motivo para prática. Os tipos de atividades de lazer foram classificados em moderados e vigorosos.

Quando foi relatada a modalidade caminhada como forma de atividade de lazer, como critério de classificação de intensidade foi questionada se a respiração permanecia normal ou mais rápida. Para classificação de pessoas ativas foram consideradas aquelas que praticavam atividade física moderada realizada cinco vezes por semana, com duração mínima de 30 minutos por sessão ou exercício físico vigoroso, três vezes por semana, por pelo menos 20 minutos por sessão. 


\section{Outras variáveis relacionadas ao consumo de alimentos:}

Neste bloco temos dois grupos: o das variáveis consideradas marcadoras de consumo alimentar saudável e o grupo que representa um consumo alimentar menos saudável. As variáveis utilizadas no primeiro grupo foram: consumo usual de peixe e de feijão. As do segundo grupo foram: consumo usual de frituras, embutidos, refrigerantes, leite integral, manteiga ou margarina, açúcares, frango com pele e carne vermelha com gordura.

As variáveis que foram coletadas no questionário telefônico por meio de uma escala de freqüência de consumo (consumo de frituras, embutidos, refrigerantes, peixe e feijão) foram transformadas em variáveis dicotômicas, segundo consumo usual: sim (recebia número um) e não (recebia número zero). Considerou-se consumo usual quando as freqüências de consumo citadas foram de "todos os dias da semana" à "um a dois dias na semana" e o consumo não usual, quando as freqüências "quase nunca" ou "nunca consome" foram citadas.

As demais variáveis de consumo que foram coletadas no questionário telefônico sem escala de freqüência, foram dicotomizadas em consumo usual (sim / não) da seguinte forma:

- Leite integral (questão 46): a alte rnativa "leite integral" recebeu o número 1 (um), sim, e as demais alternativas receberam o número 0 (zero), não. 
- Margarina e manteiga (questão 48): quando assinaladas, receberam número 1 (um), sim, e as demais alternativas receberam o número 0 (zero), não.

- Açúcares (questões 49 e 50): foi feita uma somatória das questões 49 e 50, sendo que na questão 49 , foi avaliada a utilização de açúcar para adoçar bebidas. As alternativas "somente açúcar" ou "açúcar e adoçante" receberam número 1 (um), e as demais alternativas receberam o número 0 (zero), não. $\mathrm{O}$ consumo de doces como sobremesa foi avaliado por meio da questão 50 . As alternativas "doces" e "doce ou fruta" receberam número 1(um), e as demais alternativas receberam o número 0 (zero), não.

- Carne vermelha com gordura (questão 51): quando assinalada, recebeu número 1 (um), sim, e as demais alternativas receberam o número 0 (zero), não.

- Frango com pele (questão 52): quando assinalada, recebeu número 1 (um), sim, e as demais alternativas receberam o número 0 (ze ro), não.

No questionário em anexo, as variáveis independentes aqui avaliadas estão destacadas em cor vermelha. 


\subsection{Elaboração do banco de dados}

Como as entrevistas foram realizadas por telefone, com o auxílio de um programa desenvolvido especialmente para esta pesquisa, um primeiro banco de dados já foi sendo montado automaticamente em dbf. A partir deste banco de dados primário, montourse um outro arquivo utilizando-se o programa Statistical Package for the Social Sciences (SPSS, 1992), no qual somente as variáveis de interesse foram mantidas. Foi realizada uma análise de consistência para verificar a coerência dos dados.

\subsection{Análise dos dados}

$\mathrm{Na}$ parte inicial, o conjunto de variáveis quantitativas foi descrito segundo medidas de tendência central e de dispersão. As variáveis qualitativas foram descritas por ocorrência (número de casos, porcentagem).

Para se verificar a relação entre o consumo de frutas, legumes e verduras e as variáveis quantitativas foi calculado o coeficiente de correlação de Pearson ( $r$ ) e para as variáveis qualitativas foi realizado o teste de diferença de médias de $t$-Student.

Para estimar o efeito das variáveis independentes sobre o desfecho (consumo de frutas legumes e verduras), foi utilizada análise de regressão linear múltipla hierarquizada.

A modelagem hierarquizada é uma alternativa aplicável a estudos epidemiológicos com um grande número de variáveis. A hierarquização das variáveis independentes é realizada por meio de embasamento teórico e é 
mantida durante a análise dos dados, permitindo a seleção daquelas mais fortemente associadas com o desfecho de interesse (FUCHS e col., 1996).

Para o estudo do consumo de frutas, legumes e verduras foi desenhado um modelo teórico (Figura 1) baseado nos resultados presentes na literatura. Tal modelo relaciona os possíveis fatores que estão associados ao desfecho. As variáveis independentes aqui presentes foram selecionadas a partir da literatura consultada e da disponibilidade no banco de dados da pesquisa na qual está baseado este estudo.

Visto que o consumo de alimentos dá-se de maneira diferente entre os sexos, o marco teórico aqui estabelecido será aplicado estratificado por sexo.

Segundo a técnica de análise hierarquizada (VICTORA e col, 1997), as variáveis de interesse devem ser agrupadas em blocos, ordenados de acordo com a precedência com que atuariam sobre o desfecho.

Para a seleção das variáveis que devem compor o modelo final, é necessário que haja primeiro uma análise múltipla interna em cada bloco, adotando-se um nível crítico de significância igual a 0,20 (VICTORA e col, 1997).

Após a análise intrabloco, dá-se início à modelagem hierarquizada propriamente dita. Deste modo, as variáveis sócio-demográficas constituíram o bloco mais distal do marco teórico, sendo o primeiro a ser incluído Estas variáveis permanecem como fator de ajuste para as variáveis hierarquicamente inferiores. 
O bloco seguinte, comportamental, constitui-se de variáveis selecionadas da mesma maneira: após ajuste pelo primeiro bloco, passa a ser controle para os blocos seguintes. O mesmo critério foi adotado para todos os blocos.

$\mathrm{Na}$ análise de regressão linear hierarquizada, as variáveis selecionadas são mantidas no modelo mesmo que sua significância estatística não seja preservada com a inclusão de blocos hierárquicos inferiores.

Para a interpretação dos resultados, considerou-se que a identificação de associação estatisticamente significativa $(p<0,05)$ entre uma determinada variável de estudo e a variável desfecho, após ajuste para os potenciais fatores de mesmo bloco e dos blocos hierárquicos superiores, indica a existência de um efeito independente, própria à variável em questão. A manutenção de significância estatística após a inclusão dos fatores dos blocos inferiores, aponta a existência de um efeito direto sobre a variável desfecho, ou, pelo menos, não mediado pelas variáveis mais proximais estudadas (ROSA, 1999).

A análise dos dados foi realizada utilizando-se o programa Statistical Package for the Social Sciences (SPSS, 1992), considerando-se intervalo de confiança de $95 \%$ e nível de significância de $5 \%(p \leq 0,05)$. 
1ํnível: sócio-econômico

- Escolaridade

- Densidade domicílio

- Estado civil

- Trabalho remunerado

2º nível: comportamental
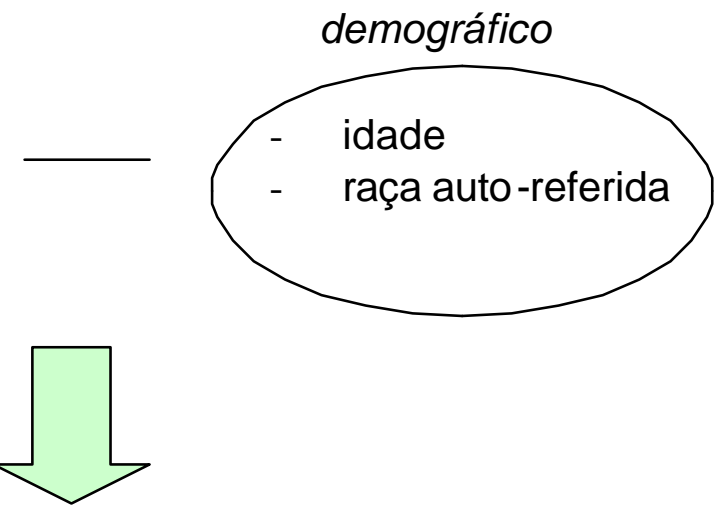

3ํo nível: $\quad$ consumo alimentar

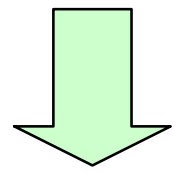

não saudável

- frituras

- embutidos

- refrigerantes

- leite integral

- manteiga/margarina

- açúcares

- frango com pele

- carne vermelha com gordura

Desfecho:

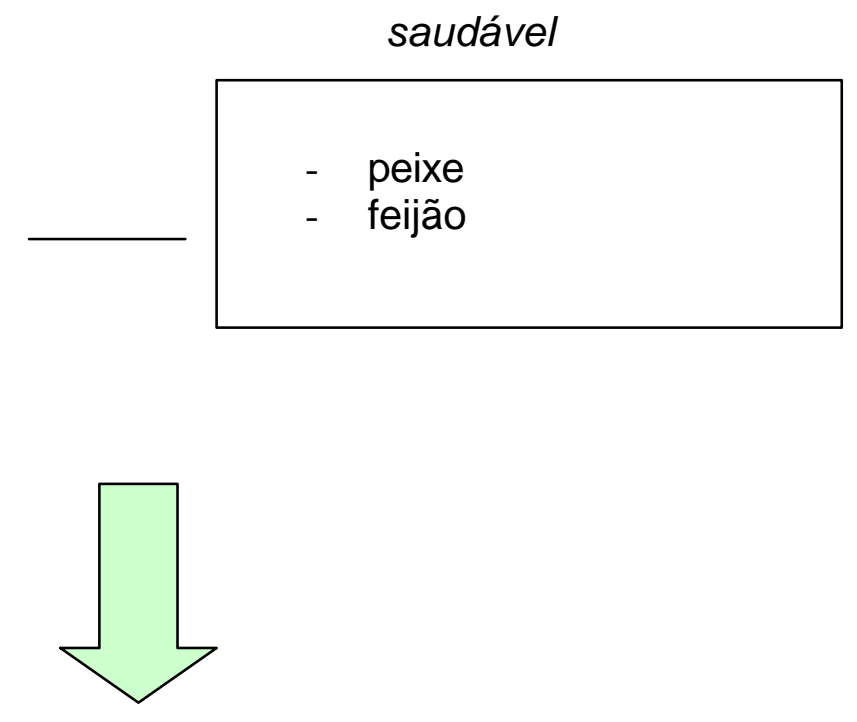

Consumo de Frutas, legumes e verduras.

Figura 1. Marco teórico, estruturado em blocos hierarquizados, para análise do consumo de frutas, legumes e verduras em adultos residentes no município de São Paulo. 


\subsection{Aspectos Éticos}

Este estudo utilizou dados do projeto já aprovado pelo Comitê de Ética da Faculdade de Saúde Pública da Universidade de São Paulo "Sistema municipal de monitoramento de fatores de risco nutricionais para doenças não transmissíveis a partir de entrevistas telefônicas: delineamento, implantação experimental e estudo de confiabilidade e validade", desenvolvido pelo NUPENS/ FSP/ USP. Contudo, este estudo foi enviado para a referida comissão de ética, obtendo parecer favorável à sua realização (Anexo 3).

Por se tratar de entrevista por telefone, o consentimento livre e esclarecido foi substituído pelo consentimento verbal (item 4 do anexo 2) obtido por ocasião do primeiro contato telefônico com o entrevistado. Nessa ocasião, foi esclarecido que os dados obtidos seriam utilizados apenas para fins de pesquisa e implantação de um sistema municipal de monitoramento de fatores de risco nutricionais para doenças crônicas não transmissíveis. 0 entrevistado foi esclarecido também quanto à possibilidade de desistir de participar do estudo a qualquer momento da entrevista e quanto à não existência de risco ou danos extras à sua saúde e à garantia de sigilo das informações fornecidas. Ao entrevistado foi fornecido um número de telefone para esclarecimento de dúvidas quanto ao projeto. 


\section{Resultados}

\subsection{Características da população de estudo}

A população de estudo foi composta por 2122 pessoas, sendo 1267 do sexo feminino e 855 do sexo masculino. A idade média das mulheres era de 43 anos ( $\mathrm{DP}=16,84$ anos), sendo que a maioria declarou ter pele branca $(54,4 \%)$ e com média de 9,39 anos de estudo (DP=4,64). Para os homens a idade média foi 39,56 anos ( $\mathrm{DP}=15$ anos), tendo a maioria declarado ter pele branca (53,9\%) e com média de 10,24 anos de estudo (DP=4,23 anos).

$\mathrm{Na}$ tabela 1, apresentam-se as características sócio-demográficas da população estudada. Houve predomínio de indivíduos nas faixas etárias de 25 a 39 anos, correspondendo a $36,7 \%$ das mulheres e a $41,8 \%$ dos homens. Entre as mulheres, 45,2\% afirmaram não ter nenhum trabalho remunerado, enquanto para os homens este número cai para $18,8 \%$. A maior parte da população estudada $(97,3 \%)$ vive em domicílios com até uma pessoa por cômodo. Apenas 2,5\% das mulheres e $2,8 \%$ dos homens residem em domicílios com duas ou mais pessoas por cômodo. 
Tabela 1: Distribuição numérica e percentual da população estudada segundo sexo e as características sócio-demográficas. São Paulo - Capital, 2003.

\begin{tabular}{|c|c|c|c|c|c|c|}
\hline & \multicolumn{2}{|c|}{ sexo feminino } & \multicolumn{2}{|c|}{$\begin{array}{c}\text { sexo } \\
\text { masculino }\end{array}$} & \multicolumn{2}{|c|}{ Total } \\
\hline & número & $\%$ & número & $\%$ & número & $\%$ \\
\hline \multicolumn{7}{|l|}{ faixa etária } \\
\hline 18 a 24 anos & 165 & 13,9 & 137 & 16,6 & 302 & 14,9 \\
\hline 25 a 39 anos & 466 & 36,7 & 342 & 41,8 & 808 & 38,7 \\
\hline 40 a 54 anos & 312 & 24,3 & 238 & 26,4 & 550 & 25,1 \\
\hline 55 a 64 anos & 150 & 11,9 & 67 & 7,1 & 217 & 10,0 \\
\hline 65 ou mais & 174 & 13,2 & 71 & 8,1 & 245 & 11,2 \\
\hline \multicolumn{7}{|l|}{ cor da pele } \\
\hline branco & 713 & 54,4 & 484 & 53,9 & 1197 & 54,2 \\
\hline não branco & 554 & 45,6 & 371 & 46,1 & 925 & 45,8 \\
\hline \multicolumn{7}{|l|}{ escolaridade* } \\
\hline \multicolumn{7}{|l|}{ (em anos de estudo) } \\
\hline 0 a 4 anos de estudo & 306 & 24,7 & 133 & 16,9 & 439 & 21,6 \\
\hline 5 a 8 anos de estudo & 161 & 13,7 & 117 & 15,1 & 278 & 14,2 \\
\hline 9 a 11 anos de estudo & 432 & 35,9 & 315 & 38,2 & 747 & 36,8 \\
\hline 12 e mais & 363 & 25,8 & 289 & 29,8 & 652 & 27,4 \\
\hline \multicolumn{7}{|l|}{ trabalha } \\
\hline $\operatorname{sim}$ & 697 & 54,8 & 692 & 81,2 & 1289 & 65,2 \\
\hline não & 570 & 45,2 & 163 & 18,8 & 733 & 34,8 \\
\hline \multicolumn{7}{|l|}{ densidade domicilio** } \\
\hline \multicolumn{7}{|l|}{ (pessoas por cômodo) } \\
\hline até 0,50 & 405 & 31,0 & 216 & 23,2 & 621 & 27,9 \\
\hline 0,51 a 1,00 & 635 & 49,6 & 435 & 51,2 & 1070 & 50,2 \\
\hline 1,00 a 2,00 & 199 & 16,8 & 181 & 22,9 & 380 & 19,2 \\
\hline Maior 2,00 & 27 & 2,5 & 23 & 2,8 & 50 & 2,6 \\
\hline \multicolumn{7}{|l|}{ estado civil } \\
\hline casados/viúvos/separados & 856 & 67,4 & 561 & 65,6 & 1417 & 66,7 \\
\hline solteiros & 411 & 32,6 & 294 & 34,4 & 705 & 33,3 \\
\hline total & 1267 & 100,0 & 855 & 100,0 & 2122 & 100,0 \\
\hline
\end{tabular}


$\mathrm{Na}$ tabela 2, apresentam-se as características comportamentais estudadas. Entre as mulheres, 17,0\% são fumantes, sendo que este número sobe para $23,9 \%$ entre os homens.

Nota-se a diferença de comportamento em relação ao sexo também para o hábito de realizar as refeições fora de casa na maior parte dos dias da semana. Entre as mulheres, 78,8\% afirmaram que não têm este hábito, já entre os homens esta proporção cai para 68,0\%. A prática de exercício físico no lazer foi reduzida tanto para os homens $(11,2 \%)$ como para as mulheres $(6,8 \%)$

Tabela 2: Distribuição numérica e percentual da população estudada segundo sexo e as variáveis comportamentais. São Paulo - Capital, 2003.

\begin{tabular}{|c|c|c|c|c|c|c|}
\hline & \multicolumn{2}{|c|}{ sexo feminino } & \multicolumn{2}{|c|}{ sexo masculino } & \multicolumn{2}{|c|}{ Total } \\
\hline & número & $\%$ & número & $\%$ & número & $\%$ \\
\hline \multicolumn{7}{|l|}{ Fuma } \\
\hline não & 1049 & 83,0 & 651 & 76,1 & 1700 & 80,3 \\
\hline $\operatorname{sim}$ & 218 & 17,0 & 204 & 23,9 & 422 & 19,7 \\
\hline \multicolumn{7}{|l|}{ Come fora } \\
\hline não & 1006 & 78,8 & 566 & 68,0 & 1572 & 74,5 \\
\hline $\operatorname{sim}$ & 261 & 21,2 & 289 & 32,0 & 550 & 25,5 \\
\hline \multicolumn{7}{|c|}{ Troca comida lanche } \\
\hline não & 1097 & 86,9 & 783 & 92,1 & 1880 & 88,9 \\
\hline $\operatorname{sim}$ & 170 & 13,1 & 72 & 7,9 & 242 & 11,1 \\
\hline \multicolumn{7}{|c|}{ Fez dieta último ano } \\
\hline não & 883 & 70,5 & 706 & 83,5 & 1589 & 75,6 \\
\hline $\operatorname{sim}$ & 384 & 29,5 & 149 & 16,5 & 533 & 24,4 \\
\hline \multicolumn{7}{|c|}{ Exercício físico lazer } \\
\hline não & 1185 & 93,2 & 764 & 88,8 & 1949 & 91,5 \\
\hline $\operatorname{sim}$ & 82 & 6,8 & 91 & 11,2 & 173 & 8,5 \\
\hline total & 1267 & 100 & 855 & 100 & 2122 & 100 \\
\hline
\end{tabular}


O consumo dos alimentos foi verificado através de freqüência de consumo simples, através de cinco categorias: todos os dias, 5 a 6 dias/semana, 3 a 4 dias/semana, 1 a 2 dias/semana, quase nunca e nunca.

$\mathrm{Na}$ tabela 3 pode-se verificar a distribuição numérica e percentual das variáveis de consumo de frutas, saladas cruas e hortaliças cozidas. Essas variáveis compuseram o escore de consumo de frutas, verduras e legumes. Verifica-se que o consumo diário de hortaliças cozidas é duas vezes maior entre as mulheres do que entre os homens

Tabela 3: Distribuição numérica e percentual da população estudada segundo sexo e as variáveis de consumo de frutas, legumes e verduras. São Paulo - Capital, 2003.

\begin{tabular}{|c|c|c|c|c|c|c|}
\hline \multirow[t]{2}{*}{ Variável } & \multicolumn{2}{|c|}{ sexo feminino } & \multicolumn{2}{|c|}{ sexo masculino } & \multicolumn{2}{|c|}{ Total } \\
\hline & número & $\%$ & número & $\%$ & número & $\%$ \\
\hline \multicolumn{7}{|l|}{ Consumo de frutas } \\
\hline todos os dias & 708 & 53,9 & 314 & 35,6 & 1022 & 46,7 \\
\hline 5 a 6 dias/semana & 75 & 5,7 & 49 & 5,1 & 124 & 5,4 \\
\hline 3 a 4 dias/semana & 171 & 13,7 & 167 & 19,6 & 338 & 16,1 \\
\hline 1 a 2 dias/semana & 168 & 14,7 & 209 & 24,1 & 377 & 18,4 \\
\hline quase nunca & 115 & 9,2 & 98 & 13,4 & 213 & 10,8 \\
\hline nunca & 30 & 2,8 & 18 & 2,2 & 48 & 2,5 \\
\hline \multicolumn{7}{|l|}{ Consumo de saladas cruas } \\
\hline todos os dias & 710 & 54,9 & 361 & 41,4 & 1071 & 49,6 \\
\hline 5 a 6 dias/semana & 106 & 8,6 & 108 & 12,5 & 214 & 10,1 \\
\hline 3 a 4 dias/semana & 201 & 16,5 & 171 & 19,6 & 372 & 17,7 \\
\hline 1 a 2 dias/semana & 151 & 12,1 & 140 & 16,9 & 291 & 14,0 \\
\hline quase nunca & 66 & 5,5 & 54 & 7,2 & 120 & 6,2 \\
\hline nunca & 33 & 2,5 & 21 & 2,4 & 54 & 2,5 \\
\hline \multicolumn{7}{|l|}{ Consumo de hortalicas cozidas } \\
\hline todos os dias & 353 & 26,5 & 113 & 13,4 & 466 & 21,3 \\
\hline 5 a 6 dias/semana & 113 & 8,3 & 57 & 6,5 & 170 & 7,6 \\
\hline 3 a 4 dias/semana & 351 & 28,2 & 215 & 24,6 & 566 & 26,8 \\
\hline 1 a 2 dias/semana & 299 & 24,7 & 308 & 34,8 & 607 & 28,7 \\
\hline quase nunca & 106 & 8,5 & 106 & 13,6 & 212 & 10,5 \\
\hline nunca & 45 & 3,8 & 56 & 7,1 & 101 & 5,1 \\
\hline total & 1267 & 100,0 & 855 & 100,0 & 2122 & 100,0 \\
\hline
\end{tabular}


Na tabela 4 pode-se verificar a distribuição numérica e percentual das demais variáveis de consumo alimentar estudadas. O consumo de fritura foi mais freqüente entre os homens. Nota-se que quase metade $(44,6 \%)$ da população feminina estudada não consumia fritura usualmente, ao passo que apenas um quarto dos homens adotava este hábito. $\mathrm{O}$ consumo de refrigerantes mostrou-se maior entre os homens, enquanto metade da população feminina estudada consome refrigerante, entre os homens a proporção é de $70,3 \%$. O consumo de frango com pele entre os homens foi duas vezes maior do que entre as mulheres. Destaca-se a alta freqüência de consumo de feijão, um alimento típico da alimentação brasileira, que não é usualmente consumido por apenas $11,4 \%$ das mulheres e 6,3\% dos homens. 
Tabela 4: Distribuição numérica e percentual da população estudada segundo sexo e variáveis dicotômicas de consumo alimentar. São Paulo - Capital, 2003.

\begin{tabular}{|c|c|c|c|c|c|c|c|}
\hline \multirow[t]{2}{*}{ Consumo usual } & & \multicolumn{2}{|c|}{ sexo feminino } & \multicolumn{2}{|c|}{ sexo masculino } & \multicolumn{2}{|c|}{ Total } \\
\hline & & número & $\%$ & número & $\%$ & número & $\%$ \\
\hline \multicolumn{8}{|l|}{ Fritura } \\
\hline & $\operatorname{sim}$ & 697 & 55,4 & 642 & 74,2 & 1339 & 62,8 \\
\hline & não & 570 & 44,6 & 213 & 25,8 & 783 & 37,2 \\
\hline \multicolumn{8}{|l|}{ Embutidos } \\
\hline & $\operatorname{sim}$ & 522 & 42,3 & 511 & 57,9 & 1033 & 48,4 \\
\hline & não & 745 & 57,7 & 344 & 42,1 & 1089 & 51,6 \\
\hline \multicolumn{8}{|l|}{ Refrigerante } \\
\hline & $\operatorname{sim}$ & 672 & 53,7 & 604 & 70,3 & 1276 & 60,3 \\
\hline & não & 595 & 46,3 & 251 & 29,7 & 846 & 39,7 \\
\hline \multicolumn{8}{|l|}{ Leite integral } \\
\hline & $\operatorname{sim}$ & 682 & 55,1 & 492 & 58,9 & 1174 & 56,6 \\
\hline & não & 585 & 44,9 & 363 & 41,1 & 948 & 43,4 \\
\hline \multicolumn{8}{|c|}{ Manteiga/margarina } \\
\hline & $\operatorname{sim}$ & 999 & 79,7 & 659 & 76,9 & 1658 & 78,3 \\
\hline & não & 268 & 20,3 & 196 & 23,1 & 464 & 21,7 \\
\hline \multicolumn{8}{|l|}{ Açúcares } \\
\hline & $\operatorname{sim}$ & 1003 & 80,5 & 744 & 88,0 & 1747 & 83,5 \\
\hline & não & 264 & 19,5 & 111 & 12,0 & 375 & 16,5 \\
\hline \multicolumn{8}{|l|}{ Frango com pele } \\
\hline & $\operatorname{sim}$ & 171 & 13,6 & 290 & 34,2 & 461 & 21,7 \\
\hline & não & 1096 & 86,4 & 565 & 65,8 & 1661 & 78,3 \\
\hline \multicolumn{8}{|c|}{ Carne vermelha com gordura } \\
\hline & $\operatorname{sim}$ & 192 & 16,8 & 258 & 32,3 & 450 & 22,9 \\
\hline & não & 1075 & 83,2 & 597 & 67,7 & 1672 & 77,1 \\
\hline \multicolumn{8}{|l|}{ Peixe } \\
\hline & $\operatorname{sim}$ & 600 & 45,8 & 456 & 49,7 & 1056 & 47,3 \\
\hline & não & 667 & 54,2 & 399 & 50,3 & 1066 & 52,7 \\
\hline \multicolumn{8}{|l|}{ Feijão } \\
\hline & $\operatorname{sim}$ & 1117 & 88,6 & 797 & 93,7 & 1914 & 90,6 \\
\hline & não & 150 & 11,4 & 58 & 6,3 & 208 & 9,4 \\
\hline & total & 1267 & 100,0 & 855 & 100,0 & 2122 & 100,0 \\
\hline
\end{tabular}


As tabelas 5 e 6 apresentam as medidas de tendência central e de dispersão para as variáveis quantitativas.

Tabela 5: Medidas de tendência central e de dispersão do consumo de FLV e variáveis sócio-demográficas para o sexo feminino. São Paulo - Capital, 2003.

\begin{tabular}{|c|c|c|c|c|}
\hline Variáveis & Média & $\begin{array}{l}\text { Desvio } \\
\text { Padrão } \\
\end{array}$ & Mínimo & Máximo \\
\hline \multicolumn{5}{|l|}{ dependente } \\
\hline $\begin{array}{l}\text { Escore FLV } \\
\text { sócio- } \\
\text { demográficas }\end{array}$ & 1,901 & 0,784 & 0,000 & 3,000 \\
\hline Idade (anos) & 42,600 & 16,752 & 18,000 & 101,000 \\
\hline Escolaridade (anos) & 9,169 & 4,567 & 0,000 & 21,000 \\
\hline Densidade domiciliar & 0,857 & 0,524 & 1,000 & 5,000 \\
\hline
\end{tabular}

Tabela 6: Medidas de tendência central e de dispersão do consumo de FLV e variáveis sócio-demográficas para o sexo masculino. São Paulo - Capital, 2003.

\begin{tabular}{lcccc}
\hline Variáveis & Média & $\begin{array}{c}\text { Desvio } \\
\text { Padrão }\end{array}$ & Mínimo & Máximo \\
\hline $\begin{array}{l}\text { dependente } \\
\text { Escore FLV }\end{array}$ & 1,542 & 0,770 & 0,000 & 3,000 \\
$\begin{array}{l}\text { sócio- } \\
\text { demográficas }\end{array}$ & & & & \\
Idade (anos) & 39,057 & 15,005 & 18,000 & 86,000 \\
Escolaridade (anos) & 9,860 & 4,216 & 0,000 & 21,000 \\
Densidade domiciliar & 0,941 & 0,571 & 1,000 & 6,000 \\
\hline
\end{tabular}

* valores ponderados pelo número de adultos no domicílio do entrevistado, multiplicado pelo inverso do número de linhas telefônicas

\subsection{Relação das variáveis independentes com o consumo de $F L V$}

Para verificar a correlação entre o escore de freqüência de consumo de FLV e as variáveis independentes quantitativas sócio-demográficas foram calculados os coeficientes de correlação de Pearson.

Entre as mulheres, as variáveis idade e escolaridade apresentaram uma correlação positiva e a variável densidade do domicílio apresentou uma correlação negativa com o cons umo de FLV (tabela 7). 
Tabela 7: Correlação das variáveis independentes quantitativas com o escore da freqüência de consumo de FLV para o sexo feminino. São Paulo - Capital 2003.

\begin{tabular}{lcc}
\hline Variáveis & $\mathbf{r}$ & $\mathbf{p}$ \\
\hline sócio-demográficas & & \\
Idade (anos) & 0,162 & $<0,001$ \\
Escolaridade (anos) & 0,161 & $<0,001$ \\
Densidade domiciliar & $-0,186$ & $<0,001$ \\
\hline
\end{tabular}

* valores ponderados pelo número de adultos no domicílio do entrevistado, multiplicado pelo inverso do número de linhas telefônicas.

Entre os homens, as variáveis idade e escolaridade apresentaram uma correlação positiva e a variável densidade domiciliar apresentou uma correlação negativa com o consumo de FLV (tabela 8).

Tabela 8: Correlação das variáveis independentes quantitativas com o escore da freqüência de consumo de FLV para o sexo masculino. São Paulo - Capital 2003.

\begin{tabular}{lcc}
\hline Variáveis & $\mathbf{r}$ & $\mathbf{p}$ \\
\hline sócio-demográficas & & \\
Idade (anos) & 0,187 & $<0,001$ \\
Escolaridade (anos) & 0,171 & $<0,001$ \\
Densidade domiciliar & $-0,193$ & $<0,001$ \\
\hline valores ponderados pelo número de adultos no domicílio do entrevistado, multiplicado pelo inverso do \\
\end{tabular}

A relação entre a freqüência de consumo de FLV e as variáveis independentes qualitativas sócio-demográficas e comportamentais estudadas apresenta-se na tabela 9 para as mulheres. Observa-se que todas as variáveis, à exceção das variáveis trabalho remunerado $(p=0,155)$ e "come fora de casa" $(p=0,308)$, apresentaram médias de freqüência de consumo de FLV diferentes em suas categorias de análise. Foi observado um maior consumo de FLV entre as mulheres brancas, não solteiras, não 
fumantes, que tenham realizado algum tipo de dieta no último ano e praticam exercício físico no lazer. Outro ponto interessante a ser destacado é que entre as mulheres que comem fora de casa e trocam œmida por lanche na maior parte dos dias da semana há um maior consumo de FLV do que entre as que não o fazem.

Tabela 9: Diferenças de médias e desvios padrão do consumo de FLV segundo as variáveis sócio-demográficas e comportamentais para o sexo feminino. São Paulo Capital, 2003.

\begin{tabular}{llcccc}
\hline Variáveis & categorias & $\mathbf{n}$ & média & dp & p \\
\hline sócio-demográficas & & & & & \\
Cor auto-referida & branco & 713 & 1,962 & 0,764 & $<0,001$ \\
& não branco & 554 & 1,828 & 0,802 & \\
Trabalho remunerado & não & 570 & 1,878 & 0,794 & 0,155 \\
& sim & 697 & 1,919 & 0,776 & \\
Estado civil & não casada & 411 & 1,803 & 0,795 & $<0,001$ \\
& casada/viúva & 856 & 1,948 & 0,775 & \\
comportamentais & & & & & \\
Fuma & não & 1049 & 1,923 & 0,783 & 0,001 \\
& sim & 218 & 1,793 & 0,784 & \\
Come fora de casa & não & 1006 & 1,893 & 0,798 & 0,308 \\
Troca comida por lanche & sim & 261 & 1,929 & 0,732 & \\
& não & 1097 & 1,883 & 0,777 & 0,002 \\
Realizou dieta no último ano & sim & 170 & 2,017 & 0,822 & \\
& não & 883 & 1,832 & 0,793 & $<0,001$ \\
Pratica exercício físico no lazer & sim & 384 & 2,067 & 0,737 & \\
& não & 1185 & 1,884 & 0,781 & $<0,001$ \\
\hline & sim & 82 & 2,136 & 0,793 & \\
\hline
\end{tabular}

* valores ponderados por fatores individuais de ponderação correspondentes ao número de adultos no domicílio do entrevistado, multiplicado pelo inverso do número de linhas telefônicas no mesmo domicílio.

A relação entre a freqüência de consumo de FLV e as variáveis independentes qualitativas sócio-demográficas e comportamentais estudadas apresenta-se na tabela 10 para os homens. As variáveis trabalho remunerado, fuma e troca comida por lanche não apresentaram médias de consumo de FLV diferentes em suas categorias de análise. Foi observado um maior consumo de FLV entre os homens brancos, solteiros, que tenham 
realizado algum tipo de dieta no último ano e praticam exercício físico no lazer.

Tabela 10: Diferenças de médias e desvios padrão do consumo de FLV segundo as variáveis sócio-demográficas e comportamentais para o sexo masculino. São Paulo Capital, 2003.

\begin{tabular}{llllll}
\hline Variáveis & categorias & $\mathbf{n}$ & média & dp & p \\
\hline sócio-demográficas & & & & & \\
Cor auto-referida & branco & 484 & 1,618 & 0,769 & $<0,001$ \\
& não branco & 371 & 1,453 & 0,763 & \\
Trabalho remunerado & não & 163 & 1,502 & 0,780 & 0,263 \\
& sim & 692 & 1,552 & 0,768 & \\
Estado civil & não casado & 294 & 1,434 & 0,757 & $<0,001$ \\
& casado/viúvo & 561 & 1,599 & 0,772 & \\
comportamentais & & & & & \\
Fuma & não & 651 & 1,557 & 0,755 & 0,129 \\
Come fora de casa & sim & 204 & 1,495 & 0,817 & \\
& não & 566 & 1,498 & 0,774 & $<0,001$ \\
Troca comida por lanche & sim & 289 & 1,636 & 0,755 & \\
& não & 783 & 1,550 & 0,768 & 0,126 \\
Realizou dieta no último ano & sim & 72 & 1,452 & 0,800 & \\
Pratica exercício físico no lazer & não & 706 & 1,505 & 0,775 & $<0,001$ \\
& sim & 149 & 1,731 & 0,717 & \\
\hline * não & 764 & 1,513 & 0,764 & $<0,001$ \\
& sim & 91 & 1,775 & 0,783 & \\
\hline
\end{tabular}
telefônicas no mesmo domicilio.

As variáveis qualitativas que representam consumo de alimentos encontram-se nas tabelas 11 , para o sexo feminino e 12, para o sexo masculino. Com exceção das variáveis "feijão", para as mulheres, "embutidos" e "manteiga ou margarina" para os homens, verifica-se que em ambos os sexos todas as variáveis apresentaram médias de freqüência de consumo de FLV diferentes em suas categorias de análise. Observa-se, também, que há maior consumo de FLV entre aqueles que adotam um comportamento alimentar mais saudável, optando por não consumir alimentos ricos em gorduras e açúcares. 
Tabela 11: Diferenças de médias e desvios padrão do consumo de FLV segundo variáveis de consumo de alimentos para o sexo feminino. São Paulo - Capital, 2003.

\begin{tabular}{llcccc}
\hline Consumo habitual & categorias & $\mathbf{N}$ & média & $\mathbf{d p}$ & $\mathbf{p}$ \\
\hline Frituras & não & 570 & 2,013 & 0,779 & $<0,001$ \\
Embutidos & sim & 697 & 1,811 & 0,777 & \\
& não & 745 & 1,953 & 0,807 & $<0,001$ \\
Refrigerantes & sim & 522 & 1,829 & 0,747 & \\
& não & 595 & 1,959 & 0,802 & $<0,001$ \\
Leite integral & sim & 672 & 1,850 & 0,766 & \\
Manteiga / margarina & não & 585 & 2,077 & 0,749 & $<0,001$ \\
Açúcares & sim & 682 & 1,757 & 0,784 & \\
& não & 268 & 2,083 & 0,799 & $<0,001$ \\
Frango com pele & sim & 999 & 1,854 & 0,774 & \\
& não & 264 & 2,261 & 0,697 & $<0,001$ \\
Carne vermelha com gordura & sim & 1003 & 1,814 & 0,780 & \\
& não & 1096 & 1,927 & 0,785 & $<0,001$ \\
Peixe & sim & 171 & 1,738 & 0,765 & \\
& não & 1075 & 1,965 & 0,774 & $<0,001$ \\
Feijão & sim & 192 & 1,582 & 0,759 & \\
& não & 667 & 1,723 & 0,794 & $<0,001$ \\
& sim & 600 & 2,112 & 0,717 & \\
& não & 150 & 1,949 & 0,871 & 0,230 \\
\hline
\end{tabular}

* valores ponderados pelo número de adultos no domicílio do entrevistado, multiplicado pelo inverso do número de linhas telefônicas no domicílio. 
Tabela 12: Diferenças de médias e desvios padrão do consumo de FLV segundo outras variáveis de consumo de alimentos para o sexo masculino. São Paulo - Capital, 2003

\begin{tabular}{|c|c|c|c|c|c|}
\hline Consumo habitual & categorias & $\mathbf{n}$ & média & dp & $p$ \\
\hline \multirow[t]{2}{*}{ Frituras } & não & 213 & 1,635 & 0,831 & \multirow{2}{*}{0,002} \\
\hline & $\operatorname{sim}$ & 642 & 1,510 & 0,746 & \\
\hline \multirow[t]{2}{*}{ Embutidos } & não & 344 & 1,531 & 0,786 & \multirow{2}{*}{0,586} \\
\hline & $\operatorname{sim}$ & 511 & 1,551 & 0,759 & \\
\hline \multirow[t]{2}{*}{ Refrigerantes } & não & 251 & 1,645 & 0,869 & \multirow{2}{*}{$<0,001$} \\
\hline & $\operatorname{sim}$ & 604 & 1,499 & 0,721 & \\
\hline \multirow[t]{2}{*}{ Leite integral } & não & 363 & 1,607 & 0,749 & \multirow{2}{*}{0,002} \\
\hline & $\operatorname{sim}$ & 492 & 1,497 & 0,782 & \\
\hline \multirow[t]{2}{*}{ Manteiga / margarina } & não & 196 & 1,595 & 0,779 & \multirow{2}{*}{0,098} \\
\hline & $\operatorname{sim}$ & 659 & 1,527 & 0,767 & \\
\hline \multirow[t]{2}{*}{ Açúcares } & não & 111 & 2,030 & 0,044 & \multirow{2}{*}{$<0,001$} \\
\hline & $\operatorname{sim}$ & 744 & 1,476 & 0,018 & \\
\hline \multirow[t]{2}{*}{ Frango com pele } & não & 565 & 1,592 & 0,776 & \multirow{2}{*}{$<0,001$} \\
\hline & $\operatorname{sim}$ & 290 & 1,446 & 0,751 & \\
\hline \multirow[t]{2}{*}{ Carne vermelha com gordura } & não & 597 & 1,614 & 0,766 & \multirow{2}{*}{$<0,001$} \\
\hline & $\operatorname{sim}$ & 258 & 1,391 & 0,758 & \\
\hline \multirow[t]{2}{*}{ Peixe } & não & 399 & 1,332 & 0,721 & \multirow{2}{*}{$<0,001$} \\
\hline & sim & 456 & 1,755 & 0,761 & \\
\hline \multirow[t]{2}{*}{ Feijão } & não & 58 & 1,834 & 0,735 & \multirow{2}{*}{$<0,001$} \\
\hline & $\operatorname{sim}$ & 797 & 1,523 & 0,769 & \\
\hline
\end{tabular}

* valores ponderados pelo número de adultos no domicílio do entrevistado, multiplicado pelo inverso do número de linhas telefônicas no domicílio.

\subsection{Análise de regressão linear múltipla hierarquizada dos fatores relacionados ao consumo de FLV.}

$\mathrm{Na}$ avaliação da influência das variáveis sócio-demográficas, comportamentais e de consumo alimentar sobre a freqüência de consumo de FLV, foi estimado um modelo de regressão linear múltiplo hierarquizado para o sexo feminino, tabela 13, e para o sexo masculino, tabela 14.

Para as mulheres, as variáveis "come fora" e "feijão" perderam significância na análise univariada (tabelas 9 e 11), permanecendo fora da 
análise de regressão linear múltipla hierarquizada. Já a variável trabalho remunerado permaneceu na modelagem como ajuste por apresentarem $\mathrm{p}<$ 0,20 na análise univariada.

$\mathrm{Na}$ análise intrabloco das variáveis sócio-demográficas, a variável cor auto-referida perdeu significância, sendo retirada da modelagem. A variável trabalho remunerado permaneceu na modelagem como ajuste, pois apresentou $p<0,20$. As demais variáveis deste bloco permaneceram estatisticamente significativas e positivamente correlacionadas ao consumo de FLV, à exceção da variável densidade domiciliar, que se mostrou inversamente correlacionada.

O mesmo procedimento de análise intrabloco foi realizado nos níveis subseqüentes. Dentre as variáveis comportamentais, todas as variáveis permaneceram significantes, sendo que o hábito de fumar mostrouse correlacionado negativamente com o consumo de FLV. As demais variáveis mostraram-se associadas positivamente.

No bloco de variáveis de consumo alimentar, as variáveis refrigerante e frango com pele perderam significância na análise intrabloco, as demais se mostraram significativamente associadas ao consumo de FLV, sendo que o consumo de peixe mostrou-se positivamente associado e as demais variáveis mostraram-se negativamente associadas ao consumo de FLV.

Iniciando a modelagem, as variáveis sócio-demográficas idade, escolaridade, densidade domiciliar e estado civil apresentaram-se significativamente associadas ao consumo de FLV, sendo que a densidade 
domiciliar foi a única variável a apresentar uma associação negativa com o consumo de FLV. A variável trabalho remunerado permaneceu no modelo como ajuste, pois apresentou $p<0,20$. Dando continuidade à modelagem, 0 bloco sócio-demográfico permanece como ajuste para o bloco comportamental.

Após este ajuste, a variável "troca comida por lanche" perdeu significância estatística e saiu da modelagem. As demais variáveis do bloco comportamental apresentam-se significativamente correlacionadas ao consumo de FLV, permanecendo como ajuste para o bloco seguinte. A única variável deste bloco que apresentou uma associação negativa com o consumo de FLV foi o hábito de fumar.

O bloco de variáveis de consumo alimentar foi ajustado pelos blocos antecessores. Todas as variáveis, exceto "embutidos", mostraram-se associadas significativamente ao consumo de FLV, sendo que aquelas que foram classificadas como pertencentes a um padrão de consumo alimentar não saudável apresentaram uma associação negativa e o consumo de peixe mostrou uma associação positiva com o consumo de FLV. 
Tabela 13 - Fatores associados ao consumo de FLV identificados mediante análise de regressão linear múltipla hierarquizada para o sexo feminino. São Paulo, 2003.

\begin{tabular}{|c|c|c|c|c|c|}
\hline $\begin{array}{l}\text { Bloco de } \\
\text { variáveis }\end{array}$ & Variáveis & $\boldsymbol{\beta}$ & IC $_{95 \%} \beta$ & $p$ & $\begin{array}{l}\text { r2 ajustado } \\
\text { ( } p \text { modelo) }\end{array}$ \\
\hline $\begin{array}{l}\text { Sócio- } \\
\text { demográfico }\end{array}$ & $\begin{array}{l}\text { idade } \\
\text { escolaridade } \\
\text { trabalho remunerado } \\
\text { densidade domiciliar } \\
\text { estado civil }\end{array}$ & $\begin{array}{c}0,011 \\
0,042 \\
0,045 \\
-0,099 \\
0,076\end{array}$ & $\begin{array}{rr}0,009 & 0,013 \\
0,035 & 0,049 \\
-0,013 & 0,103 \\
-0,156 & -0,042 \\
0,014 & 0,138\end{array}$ & $\begin{array}{l}<0,001 \\
<0,001 \\
0,131 \\
0,001 \\
0,017\end{array}$ & $\begin{array}{c}0,094 \\
(<0,001)\end{array}$ \\
\hline Comportamental & $\begin{array}{l}\text { fuma } \\
\text { dieta último ano } \\
\text { exercício físico lazer }\end{array}$ & $\begin{array}{l}-0,100 \\
0,180 \\
0,156\end{array}$ & $\begin{array}{rr}-0,171 & -0,028 \\
0,121 & 0,239 \\
0,049 & 0,263\end{array}$ & $\begin{array}{c}0,006 \\
<0,001 \\
0,004\end{array}$ & $\begin{array}{c}0,110 \\
(<0,001)\end{array}$ \\
\hline $\begin{array}{l}\text { Consumo } \\
\text { alimentar }\end{array}$ & $\begin{array}{l}\text { fritura } \\
\text { embutidos } \\
\text { leite } \\
\text { manteiga } \\
\text { açúcares } \\
\text { carne bovina c/ gordura } \\
\text { peixe }\end{array}$ & $\begin{array}{l}-0,083 \\
-0,047 \\
-0,104 \\
-0,067 \\
-0,214 \\
-0,241 \\
0,276\end{array}$ & $\begin{array}{rr}-0,139 & -0,028 \\
-0,101 & 0,006 \\
-0,159 & -0,049 \\
-0,132 & -0,002 \\
-0,284 & -0,145 \\
-0,312 & -0,171 \\
0,223 & 0,329\end{array}$ & $\begin{array}{l}0,003 \\
0,082 \\
<0,001 \\
0,044 \\
<0,001 \\
<0,001 \\
<0,001\end{array}$ & $\begin{array}{c}0,189 \\
(<0,001)\end{array}$ \\
\hline
\end{tabular}

Para o sexo masculino, as variáveis trabalho remunerado e consumo de embutidos perderam a significância ainda na análise univariada (tabelas 10 e 12) e não entraram na modelagem. Já as variáveis "fuma" e "troca comida por lanche" permaneceram na modelagem como ajuste, pois apresentavam $\mathrm{p}<0,20$ (tabela 14).

Na análise intrabloco das variáveis sócio-demográficas, as variáveis cor auto-referida e estado civil perderam a significância. As variáveis idade, 
escolaridade e densidade domiciliar permaneceram estatisticamente significantes e apresentando o mesmo comportamento verificado no sexo feminino.

Dentre as variáveis comportamentais, o tabagismo perdeu a significância na análise intrabloco e saiu da modelagem. As demais variáveis deste bloco mostraram-se associadas ao consumo de FLV. No bloco de variáveis de consumo alimentar, as variáveis leite e manteiga perderam a significância estatística e foram excluídas da modelagem. As demais variáveis permaneceram associadas significativamente ao consumo de FLV.

Iniciando a modelagem, as variáveis sócio-demográficas idade, escolaridade e densidade domiciliar permaneceram como ajuste para o bloco comportamental. Todas as variáveis desse bloco apresentaram-se significativamente associadas ao consumo de FLV e permaneceram como ajuste para o bloco seguinte, sendo que a variável "troca comida por lanche" mostrou-se associada de maneira negativa ao consumo de FLV.

O bloco de varáveis de consumo alimentar foi ajustado pelos blocos antecessores. As variáveis "fritura" e "refrigerante" perderam a significância e foram retiradas do modelo final. Variáveis que foram classificadas como pertencentes a um padrão de consumo alimentar não saudável apresentaram comportamento semelhante entre homens e mulheres, uma vez que o consumo de açúcares e carne bovina com gordura apresentaram uma correlação negativa e estatisticamente significante com o consumo de FLV. 
Tabela 14 - Fatores associados ao consumo de FLV identificados mediante análise de regressão linear múltipla hierarquizada para o sexo masculino. São Paulo, 2003.

\begin{tabular}{llllll}
\hline Bloco de variáveis & Variáveis & $\boldsymbol{B}$ & $\mathrm{IC}_{95 \%} \beta$ & $\mathbf{p}$ & $\begin{array}{c}\mathbf{2} \\
\text { ajustado } \\
\text { (p modelo) }\end{array}$ \\
\hline
\end{tabular}

$\begin{array}{llllllc}\text { Sócio-demográfico } & \text { idade } & 0,012 & 0,009 & 0,014 & <0,001 & 0,096 \\ & \text { escolaridade } & 0,039 & 0,030 & 0,047 & <0,001 & (<0,001) \\ & \text { densidade domiciliar } & -0,122 & -0,184 & -0,060 & <0,001 & \end{array}$

$\begin{array}{llccccc} & \text { exercício físico lazer } & 0,266 & 0,163 & 0,370 & <0,001 & 0,122 \\ \text { Comportamental } & \text { come fora } & 0,105 & 0,033 & 0,177 & 0,004 & (<0,001) \\ & \text { troca comida por lanche } & -0,159 & -0,278 & -0,039 & 0,009 & \\ & \text { dieta no último ano } & 0,170 & 0,083 & 0,258 & <0,001 & \end{array}$

\begin{tabular}{|c|c|c|c|c|c|c|}
\hline & $\begin{array}{l}\text { açúcares } \\
\text { frango com pele }\end{array}$ & $\begin{array}{l}-0,366 \\
-0,078\end{array}$ & $\begin{array}{l}-0,466 \\
-0,145\end{array}$ & $\begin{array}{l}-0,267 \\
-0,011\end{array}$ & $\begin{array}{l}<0,001 \\
0,022\end{array}$ & $\begin{array}{c}0,202 \\
(<0,001)\end{array}$ \\
\hline \multirow[t]{3}{*}{ Consumo alimentar } & carne bovina c/ gordura & $-0,093$ & $-0,163$ & $-0,024$ & 0,009 & \\
\hline & feijão & $-0,141$ & $-0,271$ & $-0,012$ & 0,033 & \\
\hline & peixe & 0,341 & 0,277 & 0,404 & $<0,001$ & \\
\hline
\end{tabular}

* valores ponderados pelo número de adultos no domicílio do entrevistado, multiplicado pelo inverso do número de linhas telefônicas

As figuras 2 e 3 representam, respectivamente, os fatores associados ao consumo de FLV em mulheres e homens. 
1ํ nível: sócio-econômico

- Escolaridade

- Densidade domicílio

- Estado civil

- Trabalho remunerado*

2º nível: comportamental
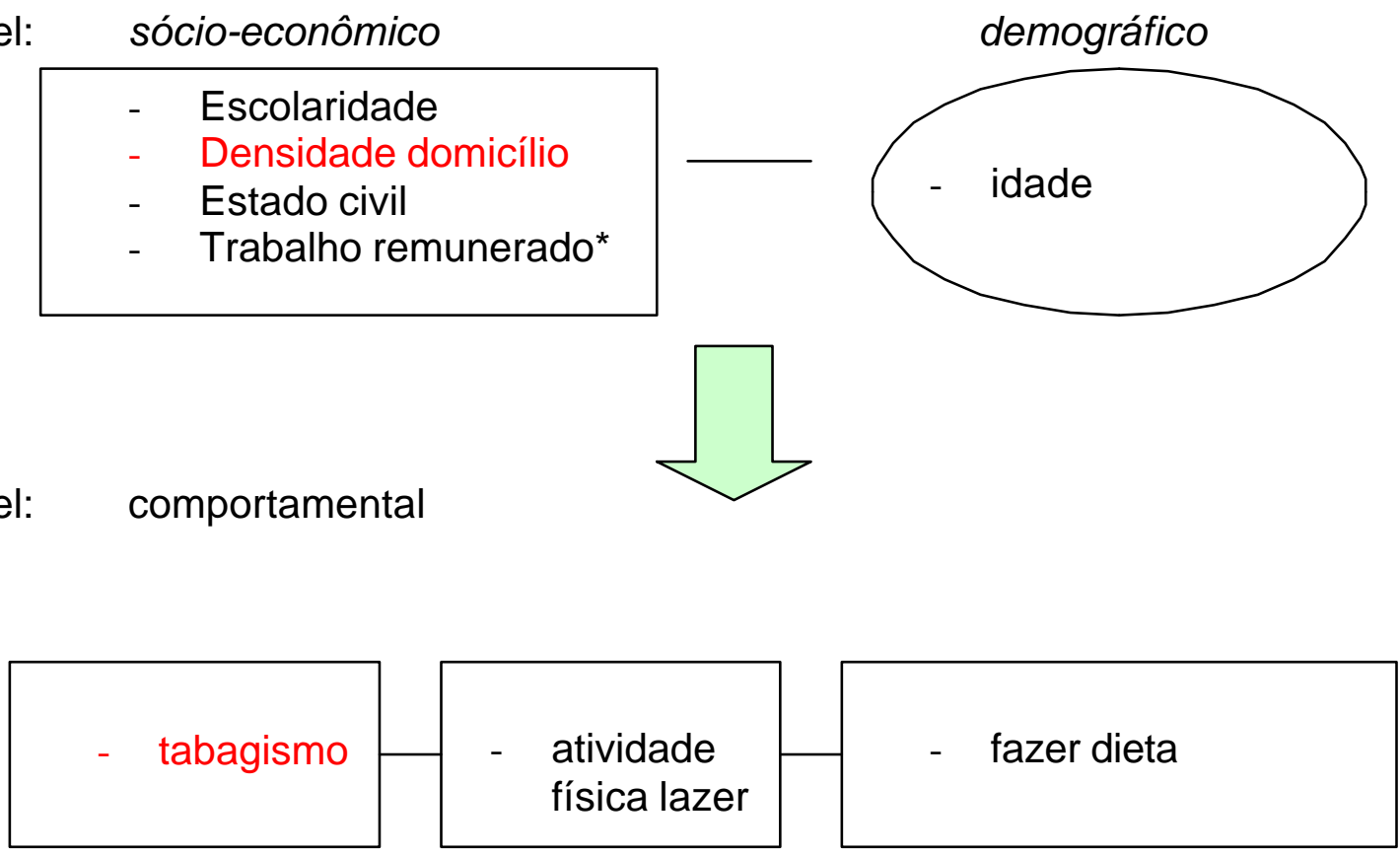

3o nível: consumo alimentar

não saudável

$\begin{array}{ll}\text { - } & \text { frituras } \\ \text { - } & \text { embutidos* } \\ \text { - } & \text { leite integral } \\ \text { - } & \text { manteiga/margarina } \\ \text { - } & \text { açúcares } \\ \text { - } & \text { carne vermelha com gordura }\end{array}$
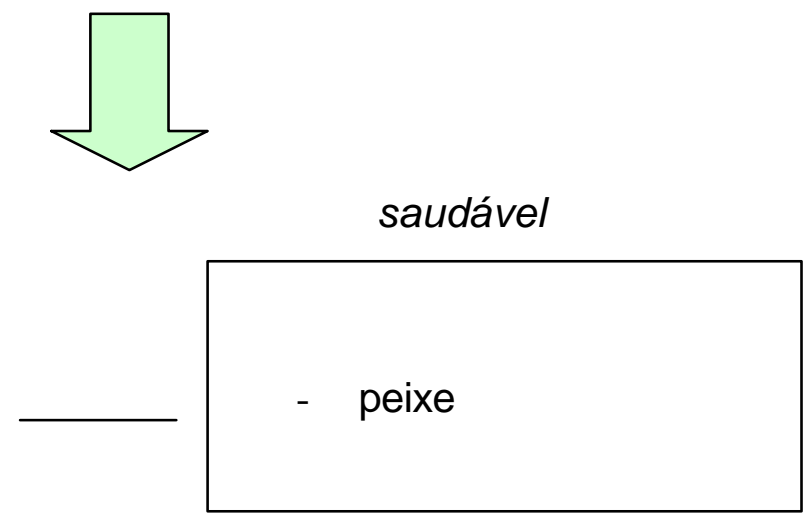

Desfecho:

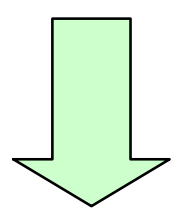

Consumo de Frutas, Legumes e Verduras.

Figura 2. Fatores associados ao consumo de frutas, legumes e verduras em adultos do sexo feminino residentes no município de São Paulo. - Modelo Final. *variáveis que permaneceram como controle variáveis destacadas em vermelho apresentam correlação negativa com o consumo de FLV. 
1ํnível: sócio-econômico

- Escolaridade

- Densidade domicílio
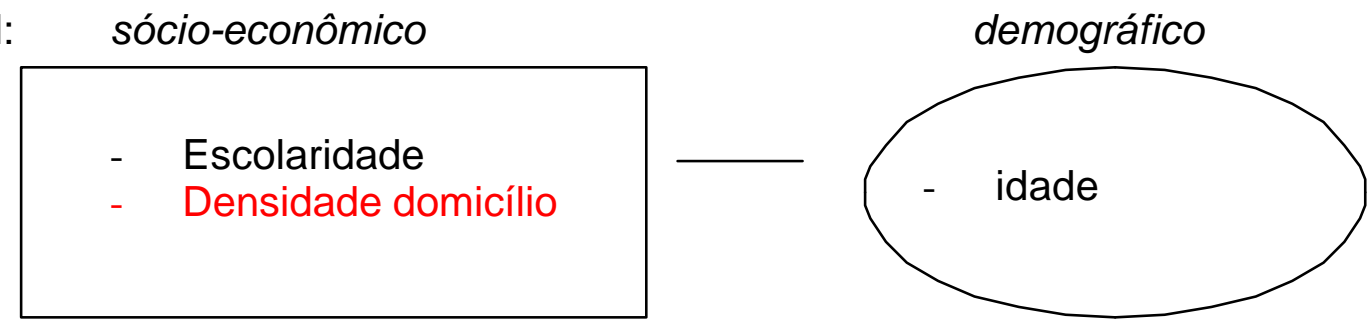

2 nível: comportamental

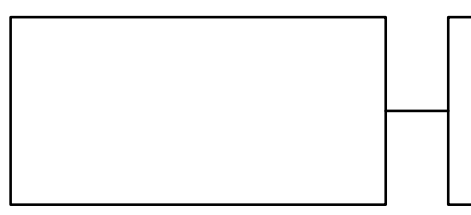

- atividade física lazer

3ํo nível: consumo alimentar

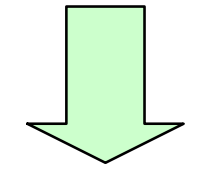

não saudável

saudável

- açúcares

- pele de frango

- carne vermelha com gordura

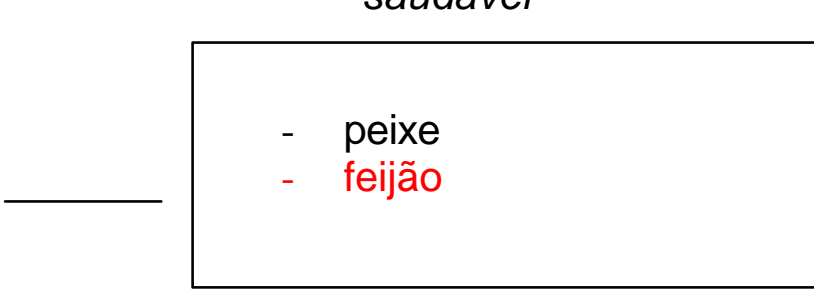

Desfecho:

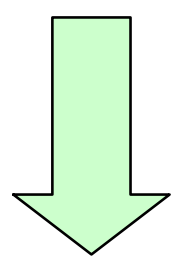

\section{Consumo de Frutas, Legumes e Verduras.}

Figura 3. Fatores associados ao consumo de frutas, legumes e verduras em adultos do sexo masculino residentes no município de São Paulo. - Modelo Final. *variáveis que permaneceram como controle variáveis destacadas em vermelho apresentam correlação negativa com o consumo de FLV. 


\section{Discussão}

Consumo inadequado de frutas, verduras e legumes é um dos cinco principais fatores associados à carga total de doenças segundo a OMS (WHO 2002). A Estratégia Global sobre Alimentação Saudável, Atividade Física e Saúde foi elaborada pela OMS preconizando a implementação de recomendações em diferentes ambientes para promover um estilo de vida saudável na população. Dentre as recomendações, encontram-se as de aumentar o consumo de FLV, cereais integrais e leguminosas (feijões), limitar a ingestão de açúcar livre, limitar a ingestão energética procedente de gorduras, substituir as gorduras saturadas por insaturadas e eliminar as gorduras trans (hidrogenadas).

No Brasil o Ministério da Saúde vem desenvolvendo ações para a prevenção e controle das doenças crônicas não transmissíveis (DCNT). O guia alimentar para a população brasileira recomenda o consumo diário de três porções de frutas e três porções de legumes e verduras e enfatiza a importância de variar o consumo desses alimentos nas diferentes refeições ao longo da semana (MINSTÉRIO DA SAÚDE, 2005).

No entanto, o consumo de FLV no Brasil é baixo. LEVY-COSTA e col (2005) em estudo sobre a distribuição e evolução da disponibilidade domiciliar de alimentos no Brasil entre os anos de 1974 e 2003 verificaram que frutas, legumes e verduras correspondem a apenas $2,3 \%$ das calorias totais da dieta, aproximadamente um terço do recomendado (400gramas diárias ou cerca de 6-7\% das calorias totais de uma dieta de $2.300 \mathrm{Kcal}$ ). 
Para orientar e encorajar a implementação de políticas públicas para o aumento do consumo de FLV é preciso conhecer a freqüência de consumo da população e seus determinantes.

O modelo de análise de regressão linear múltipla hierarquizado proposto neste trabalho possibilita identificar os fatores determinantes para 0 consumo de FLV na população estudada residente no município de São Paulo.

Foram estudadas 2122 pessoas, sendo mais da metade $(59,71 \%)$ do sexo feminino, com predomínio de indivíduos (63,8\%) entre 25 a 54 anos de idade. A maioria da população estudada declarou ter pele branca (54,2\%) e com média de 9,39 anos de estudo $(D P=4,64)$. Esses dados coincidem com os dados demográficos atuais referentes à população do município de São Paulo, onde se observava em 2004 um maior número de mulheres do que de homens, sendo que $48 \%$ da população do município de São Paulo estava na faixa etária de 25 e 59 anos. Quanto à cor auto-referida, 68,7\% das mulheres e $66,3 \%$ dos homens se declararam brancos (Fundação SEADE, 2005).

Para que os fatores determinantes do consumo de FLV pudessem ser avaliados, as variáveis estudadas foram divididas em blocos ordenados de acordo com a precedência em que atuam sobre o consumo de FLV possibilitando-nos identificar os fatores sócio-demográficos, comportamentais e de consumo alimentar relacionados ao consumo de FLV.

No bloco das variáveis sócio-demográficas, a idade e a escolaridade mostraram-se associadas positivamente ao consumo de FLV tanto para 
homens quanto para mulheres. PEARSON e col. (2005), em estudo transversal realizado em South Yorkshire, Reino Unido, verificaram que há um discreto aumento no consumo de hortaliças a medida que a idade aumenta. THOMPSON e col. (2005) em estudo multicêntrico realizado nos Estados Unidos em 38.632 domicílios também observou que entre os que têm mais anos de estudo há um maior consumo de FLV. Em estudo epidemiológico realizado no Brasil, JAIME e MONTEIRO (2005) também verificaram a influência positiva dessas duas variáveis sobre o consumo de FLV.

Além da idade e da escolaridade, a densidade domiciliar também se mostrou correlacionada ao consumo de FLV em ambos os sexos. Diversos estudos ressaltam que pessoas de baixo nível sócio-econômico têm menor consumo de FLV por razões tais como dificuldade de acesso aos alimentos, baixo poder de compra, falta de instrução, entre outras. (GISKES e col., 2002; INGLIS e col., 2005; JAIME e MONTEIRO, 2005). Neste estudo não foi verificada a renda dos entrevistados, considerando-se a variável densidade domiciliar uma proxy inversa de nível sócio-econômico, uma vez que pessoas de baixa renda geralmente possuem maior densidade domiciliar. Verificou-se uma associação negativa entre a densidade domiciliar e o consumo de FLV em ambos os sexos.

Em relação ao estado civil, os achados apontam que as mulheres não solteiras, ou seja, casadas, viúvas ou separadas, apresentam maior consumo de FLV comparado às solteiras. De modo semelhante MISHRA e col. (2005) verificaram em um estudo realizado na Austrália com mulheres 
entre 50-55 anos de idade que aquelas solteiras tinham uma alimentação menos saudável, com menor consumo de FLV.

No bloco das variáveis comportamentais, a prática de atividade física no lazer e ter realizado dieta no último ano apresentaram associação positiva com o consumo de FLV tanto em homens quanto em mulheres. Dentre estas variáveis comportamentais, o tabagismo apresentou uma associação negativa com o consumo de FLV para as mulheres.

A importância da atividade física e do combate ao tabagismo vem sendo largamente divulgada pelos diversos meios de comunicação. As mensagens veiculadas sobre alimentação e saúde ressaltam a importância do consumo de frutas, legumes e verduras. Sendo assim, a variável fazer dieta no último ano mostrou-se relacionada positivamente ao consumo de FLV, indicando a preocupação crescente das pessoas quanto à alimentação.

Resultados semelhantes puderam ser verificados em outros estudos. JAGO e col. (2005) em estudo transversal envolvendo adultos da cidade de Bogalusa, nos Estados Unidos, verificaram que o consumo de FLV era maior entre aqueles que praticavam atividade física. HE e col. (2004) em estudo de coorte realizado nos Estados Unidos com mulheres de meia idade verificaram que o maior consumo de FLV dava-se entre aquelas que praticavam mais exercício físico e não fumavam. THOMPSON e col. (2005), em estudo multicêntrico realizado nos Estados Unidos, observaram que o consumo de FLV era maior entre os que nunca haviam fumado e praticavam atividade física. Em estudo realizado com adolescentes norteamericanos, WILSON e col. (2005) verificaram que entre as meninas 
fumantes havia menor consumo de hortaliças e menor prática de atividade física.

Ainda no bloco das variáveis comportamentais, a variável "troca comida por lanche" mostrou-se inversamente associada ao consumo de frutas, legumes e verduras em adultos do sexo masculino. Possivelmente este resultado está relacionado ao fato dos homens apresentarem maior consumo usual de alimentos considerados como pertencentes a um padrão alimentar menos saudável, como açúcares. Já quanto ao hábito de comer fora de casa com freqüência estar associado a um maior consumo de FLV entre os homens pode estar relacionado a maior variedade de alimentos encontrados em restaurantes. COLAÇO (2004) em estudo qualitativo realizado com freqüentadores de diferentes praças de alimentação em São Paulo verificou que a variedade de alimentos oferecida pelos restaurantes possibilitava aos usuários uma maior diversificação da alimentação em relação às refeições realizadas no lar.

No bloco das variáveis de consumo alimentar, alimentos considerados pertencentes a um padrão alimentar não saudável, como frituras, refrigerantes, açúcares, pele de frango, carne vermelha com gordura apresentaram uma associação negativa com o consumo de FLV.

Os guias de alimentação recomendam o consumo diário de leite e derivados e diversos estudos associam esses alimentos a um padrão de consumo alimentar saudável (RUF e col., 2005; JAGO e col., 2005). Porém, esses alimentos devem ser consumidos preferencialmente desnatados ou com baixos teores de gordura. No presente estudo, a variável estudada , 
"consumo de leite integral", foi considerada um marcador de um padrão de consumo alimentar não saudável devido ao teor de gordura do alimento. Esta variável mostrou-se associada de maneira negativa com o consumo de FLV entre as mulheres.

Dentre as variáveis de consumo que representavam um padrão alimentar saudável, o consumo de peixe mostrou-se associado positivamente ao consumo de FLV, sendo um bom marcador de alimentação saudável tanto para homens quanto para mulheres. Já o consumo de feijão não mostrou associação com o consumo de FLV entre as mulheres e, entre os homens, mostrourse negativamente associado ao consumo de FLV. Porém, o consumo desse alimento está muito relacionado ao hábito alimentar do brasileiro e não se mostrou um bom marcador de alimentação saudável.

Os resultados encontrados no presente estudo, salvo raras exceções, coincidem com os dados encontrados na literatura e nos guias de recomendação de alimentação existentes.

O guia alimentar para a população brasileira (MINISTÉRIO DA SAÚDE, 2005) recomenda a diminuição do consumo de açúcares livres e diminuição de energia proveniente de gorduras. Nas análises realizadas observa-se que os alimentos ricos em açúcares e gorduras estão inversamente relacionados ao consumo de FLV. O consumo de açúcares associado negativamente ao consumo de FLV foi verificado também por FORSHEE e STOREY (2001) em estudo realizado com crianças e adolescentes. LEVY-COSTA e col. (2005) verificaram o preocupante 
aumento da disponibilidade de açúcares e a diminuição da disponibilidade de FLV nos últimos anos no Brasil.

$\mathrm{Na}$ análise desses achados é preciso considerar os limites do método empregado. Este foi um estudo epidemiológico observacional do tipo transversal. Nestes estudos, a observação de cada indivíduo se dá em uma única oportunidade e a inferência é feita pela referência dos resultados a uma população definida em local e época determinados. Como as informações são coletadas em um único momento, as suposições de causalidade não podem ser avaliadas. As informações de tempos passados são coletadas indiretamente, dependendo da memória e do interesse dos participantes em relação ao tema investigado (MEDRONHO, 2003).

Esse estudo se diferencia da grande maioria dos estudos que buscaram avaliar os determinantes do consumo de FLV porque utiliza um questionário aplicado por telefone. As investigações epidemiológicas realizadas através de ligações telefônicas são largamente utilizadas em outros países, gerando dados tão confiáveis quanto aos de inquéritos domiciliares a um menor custo. O Center for Disease Control and Prevention (CDC) desenvolveu um pequeno questionário para avaliar o consumo de FLV através de entrevistas telefônicas. Este questionário é utilizado no Sistema de Monitoramento de Fatores de Risco (Behavioral Risck Factor Surveillance System - BRFSS) realizado periodicamente nos Estados Unidos. SERDULA e col. (1993) avaliaram este breve questionário de consumo de FLV realizado por telefone com outros métodos de investigação mais extensos aplicados em diferentes cidades dos Estados Unidos. 
Verificou-se que os valores do coeficiente de correlação de Sperman variavam de 0,47 a 0,57 , apresentando uma boa correlação entre os métodos.

Com base na experiência do presente estudo, pode-se considerar que as entrevistas realizadas por telefone constituem um instrumento eficiente, rápido e econômico para realizar um inquérito epidemiológico e que o modelo de regressão linear hierarquizado é um importante instrumento para identificar os determinantes do consumo de frutas, legumes e verduras. Conhecer esses determinantes é de suma importância para encorajamento e implementação de políticas públicas de saúde que visem o aumento do consumo de FLV para promover uma alimentação mais saudável e conseqüente melhoria no estilo da vida da população. 


\section{CONCLUSÃO}

Com este estudo, pode-se concluir que:

- O padrão de consumo de frutas, legumes e verduras se diferenciou para homens e mulheres, sendo maior a freqüência de consumo no sexo feminino.

- Os determinantes do consumo de frutas, legumes e verduras foram diferentes para homens e mulheres.

- Os determinantes relacionados positivamente ao consumo de FLV tanto para homens quanto para mulheres foram: maior escolaridade, maior idade, menor densidade domiciliar, prática de atividade física no lazer, fazer dieta, não consumir usualmente açúcares e carne vermelha com gordura e consumir usualmente peixe.

- Além desses determinantes em comum, o consumo de FLV para mulheres também foi determinado por: ser ou já ter sido casada, não fumar, não consumir usualmente frituras, leite integral, manteiga e margarina.

- Entre os homens, além dos determinantes em comum, o consumo de FLV também foi determinado por comer fora do lar com freqüência, não trocar refeições por lanches freqüentemente, não consumir usualmente frango com pele e feijão. 


\section{REFERÊNCIAS BIBLIOGRÁFICAS}

Ambrosone CB, McCann SE, Freudenheim JL, Marshall JR, Zhang Y, Shields PG. Breast Cancer Risk in Premenopausal women is inversely associated with consumption of broccoli, a source of isothiocyanates, but is not modified by GST genotype.J. Nutr. 2004;134(5):1134-8.

Baker $\mathrm{AH}$, Wardle J. Sex differences in fruit and vegetable intake in older adults. Appetite 2003; 40(3): 269-75.

CDC. BRFSS in action: a state-by-state listing of how data are used. Nation Center for Chronic Disease Prevention and health Promotion. [acesso em 2003]. Disponível em http://www.cdc.gov/nccdphp.

Colaço J. Novidade, variedade e quantidade: os encontros e desencontros nas representações do comer em praças de alimentação em shoppingcenters. Mneme - Revista Virtual de Humanidades. 2004;9(3). [acesso em 22/03/2006]. Disponível em http://www.seol.com.br/mneme.

Fornés, NAS. Padrões alimentares e suas relações com os lipídios séricos em população da área metropolitana de São Paulo. [Tese de Doutorado]. São Paulo: Faculdade de Saúde Pública - USP;1998. 
Forshee RA, Storey ML. The role of added sugars in the diet quality of children and adolescents. J Am College Nutrition. 2001;20:32-43.

Fuchs SC, Victora CG, Fachel J. Modelo hierarquizado: uma proposta de modelagem aplicada à investigação de fatores de risco para diarréia grave. Ver. Saúde Pública. 1996;30(2):168-78.

Fundação SEADE. Anuário estatístico do Estado de São Paulo: 2002. São Paulo; 2006. [acesso em 8 março 2006]. Disponível em www.seade.gov.br/produtos/anuário

Gandini S, Merzenich H, Robertson C, Boyle P. Meta-analysis of studies on breast cancer risk and diet: the role of fruit and vegetable consumption and the intake of associated micronutrients. Eur. J. Cancer 2000; 36: 636-646.

Giskes K, Turrell G, Patterson C, Newman B. Socio-economic differences in fruit and vegetable consumption among Australian adolescents and adults. Public Health Nutr 2002; 5 (5):663-669.

He K, Hu FB, Colditz GA, Manson JE, Willet WC, Liu S. Changes in intake of fruits and vegetables in relation to risk of obesity and weight gain among middle-aged women. Int J Obesity. 2004;28:1569-74. 
Hyson D. The Health Benefits of Fruits and Vegetables: A Scientific Overview for Health Professionals. Wilmington, DE. Produce for Better Health Foundation 2002.

Available

at: $<$ URL.www.5aday.org/news/graphics/research doc 2002.pdf [2003]

Inglis V, Ball K, Crawford D. Why do women of low socioeconomic status have poorer dietary behaviors than women of higher socioeconomic status? A qualitative exploration. Appetite. 2005; 45(3):334-43.

Jago R, Nicklas T, Yang S, Baranowski T, Zakeri I, Berenson GS. Physical activity and health enhancing dietary behaviors in young adults: Bogalusa Heart Study. Preventive Medicine. 2005;41:194-202.

Jaime PC e Monteiro CA. Fruit and vegetable intake by Brazilian adults, 2003. Cad. Saúde Pública. 2005; 21:S19-S24.

John JH, Ziebland S, Yudkin P, Roe LS, Neil HAW. Effects of fruit and vegetable consumption on plasma antioxidant concentratios and blood pressure: a randomised controlled trial. The Lancet 2002; 359(8):1969-74.

Levy-Costa RB, Schieri R, Pontes NS, Monteiro CA. Disponibilidade domiciliar de alimentos no Brasil: distribuição e evolução (1974-2003). Ver Saúde Pública. 2005;39(4):530-40. 
Lessa, I. O adulto brasileiro e as doenças da modernidade: epidemiologia das doenças crônicas não-transmissíveis. Rio de Janeiro: Hucitec/Abrasco; 1998.

McClelland JW, Demark-Wahnefried W, Mustian RD, Cowan AT, Campbell MK. Fruit and vegetable consumption of rural African Americans: baseline survey results of the Black Churches united for Better Health 5 a Day Project. Nutr Cancer 1998; 30(2):148-57.

Ministério da Saúde. Secretaria de Atenção à Saúde. Coordenação-Geral da Política de Alimentação e Nutrição. Guia alimentar para a população brasileira : Promovendo a alimentação saudável. Brasília,DF;2005.

Mishra G, Ball K, Patterson A, Brown W, Hodge A, Dobson A. Sociodemographic inequalities in the diets of mid-aged Australian women. Eur J. Clin Nutr. 2005;59:185-95.

Mondini L, Monteiro CA. Mudanças no padrão de alimentação na população urbana brasileira (1962-1988). Rev Saúde Pública 1994; 28 (6):433-9.

Monteiro CA, Mondini L, Levy-Costa RB. Mudanças na composição e adequação nutricional da dieta familiar nas áreas metropolitanas do Brasil (1988-1996). Rev Saúde Pública 2000; 34 (3): 251-8. 
Monteiro CA, Moura EC, Jaime PC, Lucca A, Florindo AA, Figueiredo ICR, Bernal R, Silva NN. Monitoramento de fatores de risco para doenças crônicas por entrevistas telefônicas. Ver Saúde Pública. 2005;39(1):47-57.

O'Brien M, Kiely M, Galvin M, Flynn A. The importance of composite foods for estimates of vegetable and fruit intakes. Public Health Nutr 2003; 6(7):711-726 .

Pearson T, Russell J, Campbell MJ, Barker ME. Do "food deserts" influence fruit and vegetable consumption? - a cross-sectional study. Appetite. 2005;XX:1-3.

Remington PL, Smith MY, Williamson DF, Anda RF, Gentry EM, Hogelin GC. (1988). Design, characteristics, and usefulness of state-based behavioral risk factor surveillance: 1981-87. Public Health Rep 103 (4): 366-75.

Rosa TEC. Determinantes da capacidade funcional de idosos residentes no Distrito de São Paulo [dissertação de mestrado] São Paulo: Faculdade de Saúde Pública da USP; 1999.

Ruf T, Nagel G, Altenburg HP, Miller AB, Thorand B. Food and nutrient intake, anthropometric measurements and smoking according to alcohol consumption in the EPIC Heidelberg study. Ann Nutr Metab. 2005;49:16-25. 
Serdula M, Coates R, Byers T, Mokdad A, Jewell S, Chavez N e col. Evaluation of a Brief Telephone Questionnaire to Estimate Fruit and Vegetable Consumption in Diverse Study Populations. Epidemiology 1993; $4(5): 455-63$.

Steffen LM, Jacobs Jr DR, Stevens J, Shahar E, Carithers T, Folson A R. Association of whole-grain, refined-grain, and fruit and vegetable consumption with risks of all-cause mortality and incident coronary artery disease and ischemic stroke: the Atherosclerosis Risk in Communities (ARIC) Study. Am J Clin Nutr 2003;78:383-90.

Subar AF, Heimendinger J, Patterson BH, Krebs-Smith SM, Pivonka E, Kessler R. Fruit and vegetable intake in the United States: the baseline survey of the Five a Day for Better Health Program. Am. J. Health Promot. $1995 ; 9(5): 352-60$.

Thompson B, Demark-Wahnefried W, Taylor G, McClelland JW, Stables G, Havas S e col. Baseline fruit and vegetable intake among adults in seven 5 a day study centers located in diverse geographic areas. J Am Diet Assoc. 1999; 99(10):1241-8.

Thompson FE, Midthune D, Subar AF. Dietary intake estimates in the national health interview survey, 2000: methodology, results and interpretation. Journal Am Diet Association. 2005;105(3):352-63. 
Turrell G, Hewitt B, Patterson C, Oldenburg B. Measuring socio-economic position in dietary research: is choice of socio-economic indicator important? Public Health Nutrition 2003; 6 (2): 191-200.

Victora CG, Huttly SR, Fuchs SC, Olinto MTA. The role of conceptual frameworks in epidemiological analysis: a hierarchical approach. International Journal of Epidemiology. 1997;26:224-227.

Wilson DB, Smith BN, Speizer IS, Bean MK, Mitchell KS, Uguy LS, Fries EA. Differences in food intake and exercise by smoking status in adolescents. Preventive Medicine. 2005;40:872-79.

World Health Organization. The world health report 2002: reducing risks, promoting healthy life. Geneva; 2002.

World Health Organization/Food and Agriculture Organization (WHO/FAO). Diet, nutrition and the prevention of chronic diseases. Geneva; 2003. [Report of the joint WHO/FAO expert consultation]. (WHO - Technical Report Series, 916) 


\title{
Anexos
}

\section{Anexo 1}

\author{
UNIVERSIDADE DE SAO PAULO \\ NÚCLEO DE PESQUISAS EPIDEMIOLÓGICAS EM NUTRIÇÃO E SAÚDE \\ - NUPENS / USP - \\ Projeto de Pesquisa:
}

"Sistema municipal de monitoramento de fatores de risco nutricionais para doenças não transmissíveis

a partir de entrevistas telefônicas:

delineamento, implantação experimental e estudo de confiabilidade e validade"

\section{ROTEIRO DA ENTREVISTA}

1. Bom dia/tarde/noite. Meu nome é

Bom dia/tarde/noite. Meu nome é , e eu estou falando (ou eu sou, caso a ligação seja feita de outro lugar) da Faculdade de Saúde Pública da Universidade de São Paulo (USP). 0 número do seu telefone é

2. Este número de telefone é residencial ?

$\square \operatorname{sim}$

$\square$ não-Desculpe, houve um engano na identificação do seu número.

3. A pedido do Mnistério da Saúde, a Universidade de São Paulo está implantando um sistema de avaliação e acompanhamento das condições de saúde e nutrição da populacão adulta brasileira e o seu número de ta populaçáo adulta brasileira e o seu número de Inicialmente, eu preciso de sua atenção por apenas 1 minuto.

$\square$ sim-(pule para 6$)$

$\square$ não-O(a) sr(a) poderia me dizer o seu nome e qual o melhor horário para eu poder falar com o(a) sr(a) ou com outro morador da casa?

4. Anote o nome do respondente ou do "outro morador":

5. Anote o horário: _ $\quad \mathrm{h} \quad \mathrm{m}$ - Obrigado, então eu vou ligar nesse horário. Encerrar, fazer a ligação no horário indicado e retornar ao início do questionário (mencionando a ligação anterior e o nome de quem a atendeu).

6. Por favor, qual é o seu nome?

7. Qual é a sua idade ?__ anos - (Idade $\geq 18$ : pule para 10)

8. Se menor de $\mathbf{1 8}$ anos: As perguntas que eu preciso fazer tem que ser respondidas por alguém com pelo menos 18 anos. Você poderia chamar alguém de sua casa que tenha pelo menos 18 anos ?

$\square$ sim-Aguarde a pessoa e retorne para 2

$\square$ não

9. Qual o melhor horário para eu encontrar alguém com pelo menos 18 anos?

_ $\mathrm{h}$ _ $\mathrm{m}$-Obrigado, eu vou ligar nesse horário. Encerrar, fazer a ligação no horário indicado e retornar ao início do
questionário.

10. Quantas pessoas ao todo moram na sua casa ?
$\square 1$
$\square 4$
$\square 2$
$\square 10 \mathrm{e}+$
$\square 3$
$\square 6$

$\square 7$

$\square 8$

11. Quantas pessoas tem 18 anos ou mais ?
$\square 1$
$\square 4$
$\square 2$
$\square 10 \mathrm{e}+$

$\square 7$ $\square 3$
2. Bem, como essa é uma pesquisa científica, nós temos

$\square 6$

$\square 9$ que sortear uma pessoa de sua casa para responder uma breve entrevista que será feita no horário mais conveniente para essa pessoa. Para fazer o sorteio, eu preciso que o(a) sr(a) me informe a idade aproximada de todos os adultos que moram na sua casa (incluindo família e empregados que moram em casa), começando com a mais velha. Não é necessário citar o nome.

\begin{tabular}{rr}
\multicolumn{1}{c}{ № } & Nome \\
\hline 1 & \\
\hline 2 & \\
3 & \\
\hline 4 & \\
5 & \\
6 & \\
\hline 7 & \\
8 & \\
\hline 9 & \\
10 & \\
11 & \\
\hline 12 & \\
\hline
\end{tabular}

Faça o sorteio conforme as instruções recebidas, informe ao entrevistado o resultado e peça para o mesmo informar, se já não o fez, o nome da pessoa sorteada.

13. Número de ordem da pessoa sorteada:

14. Nome da pessoa sorteada:

A entrevista da pesquisa será relizada por outro membro de nossa equipe e deve durar entre 5 e 10 minutos. $O(a)$
sr(a) poderia me informar qual o melhor dia da semana $e$ horário para essa entrevista.

15. Dia da semana:

$\begin{array}{llll}\text { Dia da semana: } & & & \\ \begin{array}{l}\text { segunda } \\ \square \text { quinta }\end{array} & \square \text { domingo } & \\ \begin{array}{l}\text { terça } \\ \text { da semana }\end{array} & \square \text { sexta } & \square & \text { qualquer } \\ \square \text { quarta } & \square \text { sábado } & \square & \text { fim de }\end{array}$
dia da semana semana

16. Horário: entre he _

Agradeça, peça para o respondente avisar a pessoa sorteada sobre a pesquisa (caso o respondente não seja o sorteado) e anote em observações qualquer informação que possa facilitar a entrevista com o sorteado.

17. Nome do entrevistador:

18. Data da entrevista:

19. Observações (entrevistador): 


\section{Anexo 2}

\section{UNIVERSIDADE DE SAO PAULO \\ NÚCLEO DE PESQUISAS EPIDEMIOLÓGICAS EM NUTRIÇÃO E SAÚDE - NUPENS / USP -}

PROJETO DE PESQUISA - MUNICÍPIO SÃO PAULO

"Sistema municipal de monitoramento de fatores de risco nutricionais para doenças não transmissíveis a partir de entrevistas telefônicas"

\section{ROTEIRO DA ENTREVISTA}

1. Alô, o número do seu telefone é desculpe-se

e desligue.

2. Bom dia/tarde/noite. Meu nome é eu estou falando (ou au sou, caso a ligação seja feita de outro lugar) da Faculdade de Saúde Pública da USP. Por favor, eu gostaria de falar com:

3. Por favor, eu gostaria de falar com

Como o(a) sr(a) talvez já saiba, a pedido do Ministério da Saúde, a Universidade de São Paulo está implantando um sistema de avaliação e acompanhamento das condições de saúde e nutrição da população adulta brasileira e o seu número de telefone e o(a) sr(a) em particular foi selecionado para participar desta pesquisa.

4. A entrevista deve durar entre 5 e $\mathbf{1 0}$ minutos e o(a) sr(a) poderá interrompê-la a qualquer momento e, eventualmente, reiniciála quando achar mais oportuno. Suas respostas serão mantidas em total sigilo e utilizadas apenas para fins desta pesquisa. Caso tenha alguma dúvida sobre a pesquisa, poderá esclarecê-la diretamente na Faculdade de Saúde Pública da USP, no telefone: 3064-6068. O(a) sr(a) gostaria de anotar o telefone agora ou no final ? Podemos iniciar a entrevista?

$\square \operatorname{sim}$ (pule para 6)

$\square$ não

5. Qual o melhor horário para conversarmos ?

__ $\mathrm{h} \ldots \mathrm{m}$-Encerre, faça nova ligação para a pessoa sorteada no horário ndicado e prossiga para 6

$\square$ sorteado recusa participar

6. Anotar o horário de início da entrevista:

$$
\text { _ }
$$

7. Qual sua idade ?

anos (se menor de 21 anos, pular as questões 21 e 22, se feminino e maior de 50 pular as questões 13 e 14)

8. Sexo:

$\square$ masculino (pule para 15

$\square$ feminino

9. A sra. Já teve filhos ?

$\square \operatorname{sim}$

$\square$ não (pule para 13)
10. Quantos filhos teve?

$\begin{aligned} \square 1 & \square 3 \\ \text { ou }+\square 2 & \square 4\end{aligned}$

11. Qual a idade do mais novo ?

$\square$ menor do que 1 ano

$\square$ maior ou igual a 1 ano (pule para 13)

12. Se menor que 1 ano: Está amamentando ?

$\square \operatorname{sim}$
$\square$ não

13. A sra. está grávida no momento ?

$\square \operatorname{sim}$

não (pule para 15)

14. Em que mês aproximado da gravidez a sra está ?

$\square 1^{\circ}$

$\square 2 \stackrel{\circ}{\square} \stackrel{\circ}{\circ}$

$\square 4^{\circ}$
$\square 5$

$\square 70$

5. No momento, o(a) sr(a) está freqüentando algum curso ou faculdade?

$\square \operatorname{sim}$

$\square$ não (pule para 17)

16. Qual curso ou faculdade?

$\square$ curso $1^{\circ}$ grau pule para 20

$\square$ curso $2^{\circ}$ grau pule para 20 )

$\square$ supletivo de $1^{\circ}$ grau (pule para 20 )

supletivo de $2^{\circ}$ grau (pule para 20 )

$\square$ curso superior pule para 20 )

$\square$ curso de pós-graduação (pule para 20)

$\square$ outro curso (prossiga para 17)

17. Até que idade o(a) sr(a) estudou?

anos

$\square$ nunca estudou (pule para 20)

$\square$ não lembra (pule para 20 )

18. Até que série e grau o(a) sr(a) estudou ?

$\begin{array}{cl}\square 1 & \square \text { curso primário } \\ \square 2 & \square \text { curso ginasial } \\ \square 3 & \square 1^{\circ} \text { grau } \\ \square 4 & \square 2^{\circ} \text { grau ou colégio ou normal } \\ \text { ou técnico } & \square \text { supletivo de } 1^{\circ} \text { grau } \\ \square 5 & \square \text { supletivo de } 2^{\circ} \text { grau } \\ \square 6 & \square \text { curso superior } \\ \square 7 & \end{array}$




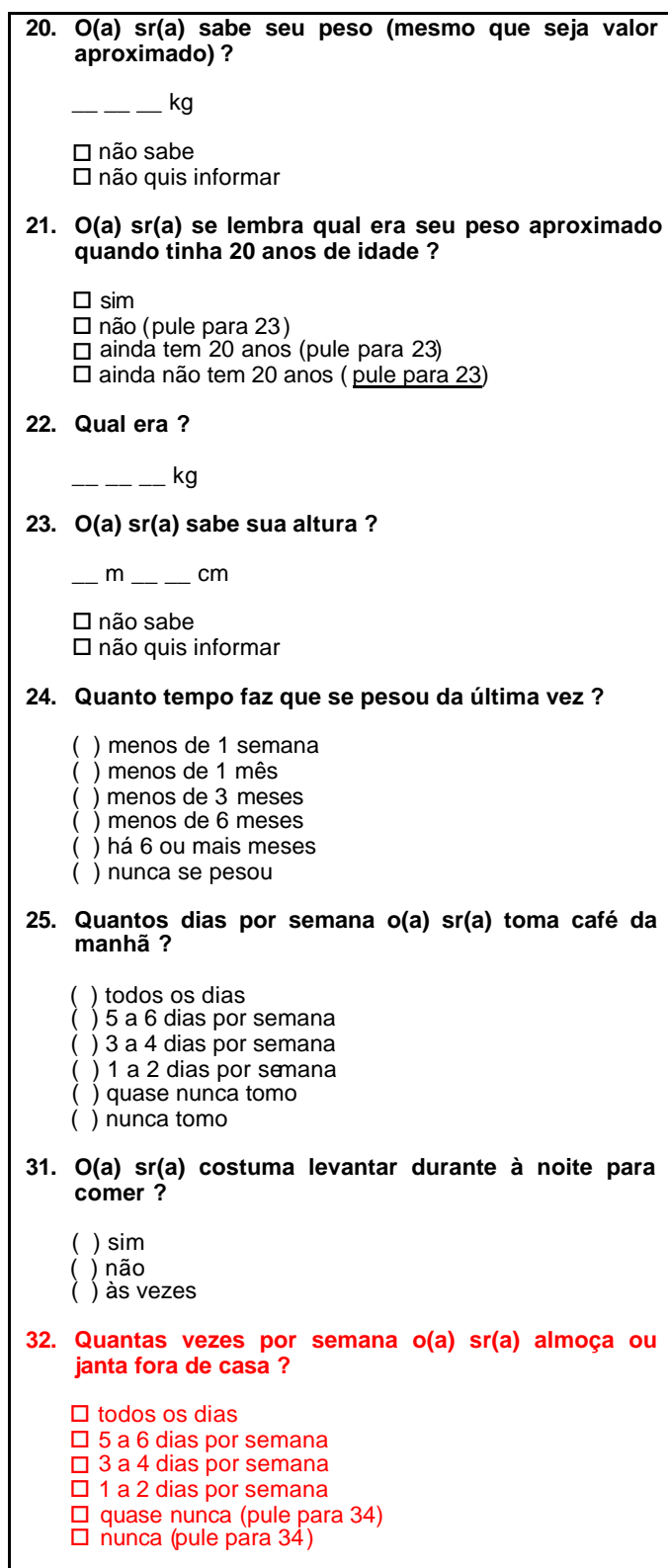

33. Quando o(a) sr(a) almoça ou janta fora de casa, o que é mais comum comer?
( ) lanche (sanduíche, salgado, pastel, pizza) ( ) comida (arroz, feijão, carne, salada, legumes,
macarrão)
$\square$ refere que come igualmente lanche e comida

34. Quantas dias por semana o(a) sr(a) troca o almoço ou jantar por lanche? $\square$ todos os dias

$\square 5$ a 6 dias por semana

$\square 3$ a 4 dias por semana

$\square$ a 2 dias por semana

$\square$ quase nunca

$\square$ nunca

Agora vou listar alguns alimentos, e o(a) sr(a) vai me dizer quantos dias na semana o(a) sr(a) costuma comer cada um desses alimentos.

34. b) Quantos dias na semana o(a) sr(a) come feijão ?

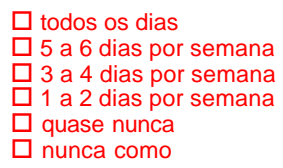

35. Quantos dias na semana o(a) sr(a) come carne de vaca?

$$
\begin{aligned}
& \square \text { todos os dias } \\
& \square 5 \text { a } 6 \text { dias por semana } \\
& \square 3 \text { a } 4 \text { dias por semana } \\
& \square \text { a } 2 \text { dias por semana } \\
& \square \text { quase nunca como } \\
& \square \text { nunca como (pule a } 51 \text { ) }
\end{aligned}
$$

36. Quantos dias na semana o(a) $\operatorname{sr}(a)$ come frutas ?

$$
\begin{aligned}
& \square \text { todos os dias } \\
& \square 5 \text { a } 6 \text { dias por semana } \\
& \square 3 \text { a } 4 \text { dias por semana } \\
& \square \text { a } 2 \text { dias por semana } \\
& \square \text { quase nunca como } \\
& \square \text { nunca como }
\end{aligned}
$$

37. Quantos dias na semana o(a) sr(a) come alimentos fritos em óleo (como batata frita, ovo frito, pastel, coxinha)?

$$
\begin{aligned}
& \square \text { todos os dias } \\
& \square 5 \text { a } 6 \text { dias por semana } \\
& \square \text { a } 4 \text { dias por semana } \\
& \square \text { a } 2 \text { dias por semana } \\
& \square \text { quase nunca como } \\
& \square \text { nunca como }
\end{aligned}
$$

38. Quantos dias na semana o(a) $\operatorname{sr}(a)$ come salada crua? (Ex: alface, tomate, pepino)

$$
\begin{aligned}
& \square \text { todos os dias } \\
& \square 5 \text { a } 6 \text { dias por semana } \\
& \square 3 \text { a } 4 \text { dias por semana } \\
& \square 1 \text { a } 2 \text { dias por semana } \\
& \square \text { quase nunca como } \\
& \square \text { nunca como }
\end{aligned}
$$

39. Quantos dias na semana o(a) sr(a) toma refrigerante

$$
\begin{aligned}
& \square \text { todos os dias } \\
& \square \text { a } 6 \text { dias por semana } \\
& \square \text { a } 4 \text { dias por semana } \\
& \square \text { 1 a } 2 \text { dias por semana } \\
& \square \text { quase nunca tomo (pule para 42) } \\
& \square \text { nunca tomo (pule para 42) }
\end{aligned}
$$




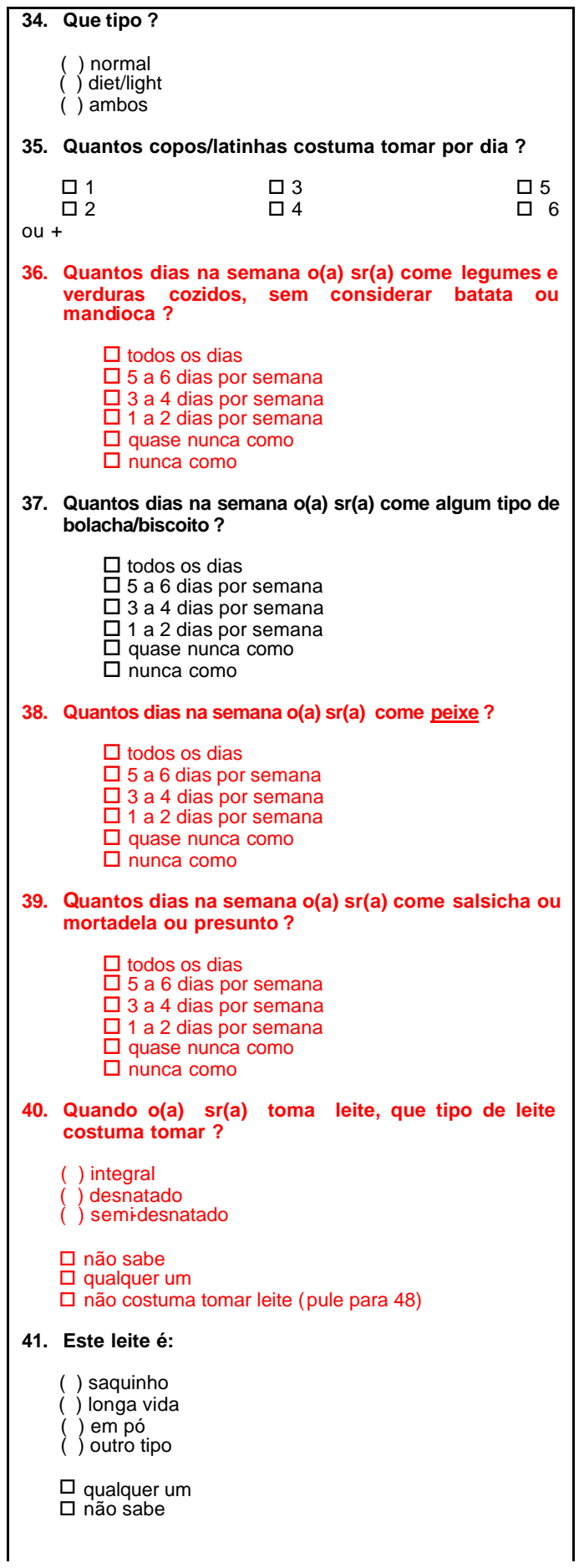

42. Quando o(a) sr(a) come pão/bolacha/torrada costuma passar com mais freqüêencia:

( ) manteiga

() nenhum dos dois

$\square$ não sabe

$\square$ não come pão/bolacha/torrada

43. Quando o(a) $\operatorname{sr}(a)$ adoça chá, café, suco ou leite costuma usar:

( ) adoçante

( ) àsúcar vezes adoçante/às vezes açúcar

$\square$ não adoça nem com açúcar, nem com adoçante

44. Quando o(a) sr(a) come sobremesa, o(a) $\operatorname{sr}($ a) costuma comer com mais freqüência:

\}$\left\{\begin{array}{l}\text { doces } \\ \text { frutas }\end{array}\right.$

$\square$ os dois igualmente

$\square$ não costuma comer sobremesa

45. Quando o(a) $\mathrm{sr}$ (a) come carne vermelha com muita gordura o(a) sr(a) costuma:
( ) tirar o excesso de gordura
() comer com a gordura
$\square$ não come carne vermelha com muita gordura

46. Quando o(a) sr(a) come pedaços de frango com pele, o(a) sr(a) costuma:

( ) tirar a pele

( ) comer com a pele

$\square$ não come pedaços de frango com pele

47. Quantos dias na semana o(a) sr(a) come carne ou frango feito na brasa tipo churrasco ?

$\square$ todos os dias

$\square 5$ a 6 dias por semana

$\square 3$ a 4 dias por semana

$\square 1$ a 2 dias por semana

1 a 2 dias por seman
1 a 2 vezes por mês

$\square$ quase nunca como

$\square$ quase nunca como

48. $O(a) \operatorname{sr}(a)$ está fazendo atualmente alguma dieta ?

$\square \operatorname{sim}(\operatorname{sim}$ pule a 55$)$

$\square$ não

49. Nos últimos doze meses, o(a) $\operatorname{sr}(a)$ fez alguma dieta?

$\square \operatorname{sim}$

$\square$ não

50. Se a pessoa mencionou que já fez ou faz dieta: Qual o principal motivo que fez o(a) sr(a) fazer dieta ?

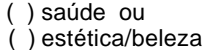
$\square$ saúde e estética
$\square$ outro motivo
$\square$ não quis informar
$\square$ não sabe informar 
34. Atualmente o(a) sr(a) está tomando algum produto ou medicamento para perder peso?

$\square \operatorname{sim}($ pule a 58)

$\square$ não

$\square$ não quis informar

35. Nos últimos doze meses, o(a) sr(a) tomou algum produto ou medicamento para perder peso ?

\section{$\square \operatorname{sim}$}

não

$\square$ não quis informar

36. Quantos dias na semana o(a) sr(a) toma alguma bebida alcoólica?

$\square$ todos os dias

$\square$ a 6 dias por semana

ㄱ 3 a dias por semana

1 a 2 dias por semana

$\square$ quase nunca tomo (pule para 62)

$\square$ nunca tomo (pule para 62)

37. Num único dia o(a) $\operatorname{sr}(a)$ chega a tomar mais do que 2 latas de cerveja ou mais do que 2 taças de vinho ou mais do que 2 doses de qualquer outra bebida alcoólica?

$\square \operatorname{sim}$

não (pule para 62)

38. Isso ocorre :

( ) quase todos os dias

( ) pelo menos 1 vez por semana

( ) pelo menos 1 vez por mês

( ) pelo menos 1 vez por ano

$\square$ não sabe

Nas próximas questões, vamos perguntar sobre suas atividades físicas do diaa-dia.

39. $O(a) \operatorname{sr}(a)$ faz ou pratica algum tipo de exercício físico ou esporte?

$\square \operatorname{sim}$

$\square$ não (pule para 69)

40. Qual o tipo principal de exercício físico ou esporte que o(a) sr(a) pratica?

$\square$ caminhada

$\square$ corrida (pule para 65)

$\square$ caminhada em esteira (pule para 65)

$\square$ corrida em esteira (pule para 65)

$\square$ musculação (pule para 65)

$\square$ ginástica aeróbica (pule para 65 )

$\square$ hidroginástica (pule para 65 )

$\square$ ginástica em geral (pule para 65)

$\square$ natação (pule para 65)

$\square$ artes marciais e lutas (pule para 65)

$\square$ bicicleta (pule para 65 )

$\square$ futebol (pule para 65)

$\square$ basquetebol (pule para 65)

$\square$ voleibol (pule para 65)

$\square$ tênis (pule para 65)

$\square$ outros (pule para 65 )
41. Se a pessoa mencionar caminhada: Quando o(a) sr(a) faz caminhada a sua respiração costuma ficar:

( ) igual a de sempre

( ) um pouco aumentada

$\square$ não sabe

42. $\mathrm{O}$ (a) $\operatorname{sr}(\mathrm{a})$ pratica ... (mencionar o exercício) pelo menos uma vez por semana?

$\square \operatorname{sim}$

$\square$ não - (pule para 69)

43. Quantos dias por semana o(a) $\operatorname{sr}(a)$ costuma praticar ... (mencionar o exercício) ?

( ) todos os dias

( ) 5 a 6 dias por semana

( ) 3 a 4 dias por semana

( ) 1 a 2 dias por semana

$\square$ quase nunca

$\square$ nunca

44. No dia que o(a) sr(a) pratica ... mencionar o exercício) quanto tempo dura esta atividade?

( ) menos que 20 minutos

( ) 30 minutos

( ) 45 minutos

( ) 60 minutos ou mais

45. Qual o motivo principal para o(a) $\operatorname{sr}(a)$ praticar ... (mencionar o exercício) ?

( ) diversão ou

( ) saúde ou

( ) estética/beleza

$\square$ diversão e saúde

$\square$ saúde e estética

$\square$ outro motivo

$\square$ não sabe informar

46. No momento o(a) sr(a) está trabalhando ?

$\square \operatorname{sim}$

$\square$ não (pule para 76)

47. Qual seu tipo de trabalho ou ocupação principal ? Anote:

48. Quantas horas por dia o(a) sr(a) trabalha ?

( ) menos de 6 horas

() 6 a 8 horas

( ) 8 horas ou mais

49. Quantos dias na semana o(a) sr(a) trabalha ?

( ) menos que 3 dias

( ) 3 a 4 dias

( ) 5 ou mais dias 
34. Com relação ao esforço físico, o(a) sr(a) classificaria seu tipo de trabalho como:
( ) muito pesado
( ) pesado
( ) leve
( ) muito leve
$\square$ não sabe

35. Para ir de sua casa para o trabalho, o(a) $\operatorname{sr}(a)$ costuma ir de:

( ) carro/moto (pule para 76)

( ) ônibus/metrô/trem/van (pule para 76)

( ) caminhando

( ) bicicleta

$\square$ trabalha em casa (pule para 76)

36. Quanto tempo aproximadamente o(a) $\operatorname{sr}(a)$ gasta para chegar ao trabalho?

( ) menos de 15 minutos

( ) 15 minutos

( ) 30 minutos

( ) 60 ou mais minutos

37. $O$ (a) sr(a) é quem costuma fazer a limpeza pesada de sua casa?

$\square \operatorname{sim}$

$\square$ não

$\square$ costuma ajudar

38. $O$ (a) $\operatorname{sr}(a)$ costuma assistir televisão todos os dias ?

$\square \operatorname{sim}($ pule para 79)

$\square$ não

39. Quantos dias por semana o(a) sr(a) costuma assistir televisão?

5 a 6 dias por semana

3 a 4 dias por semana

$\square 1$ a 2 dias por semana

$\square$ não costuma assistir televisão (pule para 80 )

40. Quantas horas por dia o(a) sr(a) costuma assistir televisão?

( ) menos de 1 hora por dia

( ) entre 1 e 2 horas por dia

( ) entre 3 e 4 horas por dia

() entre 5 e 6 horas por dia

( ) 6 ou mais horas por dia

41. Quantas horas aproximadamente por noite o(a) $\operatorname{sr}(a)$ costuma dormir?

( ) menos de 6 horas por dia

( ) 7 horas por dia

() 8 horas por dia

( ) 9 ou mais horas por dia

$\square$ pessoa trabalha no período noturno

Agora estamos chegando ao final do questionário e gostariamos de saber sobre seu estado de saude.
42. $O$ (a) $\operatorname{sr}(a)$ classificaria seu estado de saúde como:

$$
\begin{aligned}
& \text { ( ) } \begin{array}{l}
\text { excelente, } \\
\text { bom, }
\end{array} \\
& \text { (2) } \begin{array}{l}
\text { regular ou } \\
\text { ruim }
\end{array} \\
& \square \text { não sabe } \\
& \square \text { não quis informar }
\end{aligned}
$$

43. Algum médico já lhe disse que o(a) $\operatorname{sr}(a)$ tem pressão alta?

$\square$ sim

44. E diabetes ?

$\square \operatorname{sim}$

45. E doenças do coração ?

ㅁ $\operatorname{sim}$

46. E colesterol elevado?

$\square \operatorname{sim}$
$\square$ não

47. E osteoporose ?

$\square \operatorname{sim}$

$\square$ não

48. $O(a) \operatorname{sr}(a)$ fuma ?

$$
\begin{aligned}
& \square \operatorname{sim} \\
& \square \text { não (pule para 91) } \\
& \square \text { não quis informar (pule para 94) }
\end{aligned}
$$

49. Quantos cigarros o(a) sr(a) fuma por dia ?
$\square 1-4$
$\square$ 15-19
$\square 40 \mathrm{e}+$
$\square 20-29$
व $10-14$
궁-39

50. Que idade o(a) sr(a) tinha quando começou a fumar regularmente?

$$
\text { anos }
$$

51. $O(a) \operatorname{sr}(a)$ já tentou parar de fumar ?

$\square \operatorname{sim}$ (pule para 94)

$\square$ não (pule para 94

52. $\mathrm{O}(\mathrm{a}) \mathrm{sr}(\mathrm{a})$ já fumou ?

$\square \operatorname{sim}$

$\square$ não (pule para 94)

53. Que idade o(a) sr(a) tinha quando começou a fumar?

__ anos

54. Que idade o(a) sr(a) tinha quando parou de fumar? 
Para finalizar, nós precisamos saber:

34. Qual seu estado civil atual ?
( ) solteiro
( ) casado
( ) viúvo/separado

35. A cor de sua pele é:
( ) branca
( ) negra
) parda ou morena
( ) amarela
$\square$ não sabe
$\square$ não quis informar

36. Quantos cômodos têm na sua casa, não contando o banheiro (conte quartos, salas, copa e cozinha)?
$\square 1$
$\square 4$
ㅁ 7
$\square 2$
$\square 3$
$\square 10 \mathrm{e}+$
$\square 8$
$\square 9$

37. Quantas pessoas moram na sua casa?
$\square 1$
$\square 4$
$\square 7$
$\square 2$
$\square 10 \mathrm{e}+$
$\square 5$
$\square 6$
$\square 8$

38. Além desta linha existe outra linha fixa de telefone em sua casa?

$\square \operatorname{sim}$

$\square$ não (pule para 100)

39. Quantas?

_ linhas

100. $\mathrm{O}$ (a) $\mathrm{Sr}(\mathrm{a})$. pode me dizer o nome do seu bairro?

Anote:

Sr(a)

Nós agradecemos muito pela sua colaboração. Se tivermos alguma dúvida voltaremos a Ihe telefonar.

Se não anotou o telefone no início da pesquisa: Gostaria de anotar o número de telefone da USP ?

Se sim: O número é 3064-6068

Anotar o horário de término:

$\mathrm{h} \ldots \mathrm{m}$

Nome do entrevistador:

Data da entrevista:

- -

Observações (entrevistador): 


\section{Anexo 3}

Anexo 3

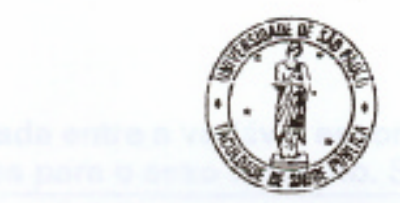

\section{Universidade de São Paulo}

Faculdade de Saúde Pública

COMITE DE ETICA-COEP

Áv. Dr. Árnaido, 715 - CEP 01246-904 - São Pauio - Brasil

Telefones: (55-1i) 3066- 7779 - fone/fax (55-11) 3064 -7314 - e-maii: mderacas@usp.br

\section{Of.COEP/070/04}

02 de abril de 2004

Pelo presente, informo que o Comitê de Ética em Pesquisa da Faculdade de Saúde Pública da Universidade de São Paulo-COEP, analisou e aprovou o protocolo de pesquisa n. ${ }^{\circ} 1143$, intitulado "AVALIAÇÃO DO PADRÃO DO CONSUMO DE FRUTAS, LEGUMES E VERDURAS EM ADULTOS RESIDENTES NO MUNICÍPIO DE SÃO PAULO.", apresentado pela pesquisadora Iramaia Campos Ribeiro Figueiredo.

O projeto faz parte de uma pesquisa mais ampla, intitulada: "SISTEMA MUNICIPAL DE MONITORAMENTO DE FATORES DE RISCO NUTRICIONAIS PARA DOENÇAS NÃO TRANSMISSIVEIS A PARTIR DE ENTREVISTAS TELEFÔNICAS: DELINEAMENTO, IMPLANTAÇÃO EXPERIMENTAL E ESTUDO DE CONFIABILIDADE E VALIDADE", do pesquisador Carios Augusto Monteiro, já analisada e aprovada por este Comitê em reunião realizada em 13.05.2003, não havendo modificações relativas ao conteúdo da pesquisa original.

Atenciosamente,

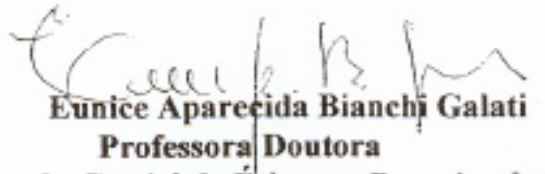

Coordenadora do Comitê de Ética em Pesquisa da FSP-COEP 


\section{Anexo 4}

\section{Análise univariada entre a variável escore FLV e variáveis} independentes para o sexo feminino. São Paulo, 2003.

\begin{tabular}{|c|c|c|c|c|c|}
\hline Variáveis & $\mathbf{r}$ & $\beta$ & IC 95 & & $p$ \\
\hline escolaridade & 0,171 & 0,029 & 0,020 & 0,038 & $<0,001$ \\
\hline densidade domiciliar & 0,207 & $-0,321$ & $-0,405$ & $-0,238$ & $<0,001$ \\
\hline estado civil & 0,094 & 0,159 & 0,066 & 0,251 & $<0,001$ \\
\hline trabalho remunerado & 0,027 & 0,043 & $-0,044$ & 0,130 & 0,335 \\
\hline idade & 0,167 & 0,008 & 0,005 & 0,010 & $<0,001$ \\
\hline cor & 0,083 & $-0,132$ & $-0,219$ & $-0,045$ & $<0,001$ \\
\hline tabagismo & 0,060 & $-0,125$ & $-0,240$ & $-0,010$ & 0,002 \\
\hline exercício físico no lazer & 0,087 & 0,279 & 0,103 & 0,455 & $<0,001$ \\
\hline come fora? & 0,019 & 0,036 & $-0,033$ & 0,105 & 0,308 \\
\hline troca comida por lanche & 0,058 & 0,134 & 0,051 & 0,217 & 0,002 \\
\hline dieta & 0,109 & 0,186 & 0,093 & 0,280 & $<0,001$ \\
\hline fritura & 0,128 & $-0,203$ & $-0,259$ & $-0,146$ & $<0,001$ \\
\hline embutidos & 0,056 & $-0,089$ & $-0,177$ & $-0,001$ & $<0,001$ \\
\hline refrigerante & 0,081 & $-0,127$ & $-0,214$ & $-0,041$ & $<0,001$ \\
\hline leite & 0,209 & $-0,330$ & $-0,415$ & $-0,245$ & $<0,001$ \\
\hline manteiga/margarina & 0,111 & $-0,213$ & $-0,319$ & $-0,108$ & $<0,001$ \\
\hline açúcares & 0,233 & $-0,452$ & $-0,556$ & $-0,348$ & $<0,001$ \\
\hline frango com pele & 0,099 & $-0,227$ & $-0,354$ & $-0,101$ & $<0,001$ \\
\hline carne vermelha com gordura & 0,197 & $-0,433$ & $-0,551$ & $-0,314$ & $<0,001$ \\
\hline peixe & 0,256 & 0,403 & 0,319 & 0,487 & $<0,001$ \\
\hline feijão & 0,002 & 0,006 & $-0,128$ & 0,140 & 0,929 \\
\hline
\end{tabular}




\section{Anexo 5}

Análise univariada entre a variável escore FLV e variáveis independentes para o sexo masculino. São Paulo, 2003.

\begin{tabular}{lrrrrr}
\hline \multicolumn{1}{c}{ Variáveis } & $\mathbf{r}$ & $\boldsymbol{\beta}$ & \multicolumn{2}{c}{$\mathbf{I C}_{95 \%} \boldsymbol{\beta}$} & \multicolumn{1}{c}{$\boldsymbol{p}$} \\
\hline escolaridade & 0,170 & 0,031 & 0,019 & 0,043 & $<0,001$ \\
densidade domiciliar & 0,198 & $-0,269$ & $-0,358$ & $-0,180$ & $<0,001$ \\
estado civil & 0,107 & 0,174 & 0,065 & 0,283 & 0,002 \\
trabalho remunerado & 0,006 & 0,013 & $-0,120$ & 0,145 & 0,853 \\
idade & 0,206 & 0,011 & 0,007 & 0,014 & $<0,001$ \\
cor & 0,077 & $-0,121$ & $-0,225$ & $-0,016$ & 0,024 \\
tabagismo & 0,049 & $-0,089$ & $-0,211$ & 0,033 & 0,153 \\
exercício físico no lazer & 0,135 & 0,340 & 0,173 & 0,508 & $<0,001$ \\
come fora? & 0,083 & 0,137 & 0,064 & 0,211 & $<0,001$ \\
troca comida por lanche & 0,035 & $-0,099$ & $-0,225$ & 0,028 & 0,126 \\
dieta & 0,111 & 0,227 & 0,091 & 0,363 & 0,001 \\
fritura & 0,071 & $-0,124$ & $-0,202$ & $-0,046$ & 0,002 \\
embutidos & 0,002 & $-0,004$ & $-0,110$ & 0,102 & 0,944 \\
refrigerante & 0,105 & $-0,178$ & $-0,292$ & $-0,065$ & 0,002 \\
leite & 0,084 & $-0,132$ & $-0,237$ & $-0,027$ & 0,014 \\
manteiga/margarina & 0,061 & $-0,113$ & $-0,237$ & 0,011 & 0,073 \\
açúcares & 0,234 & $-0,539$ & $-0,690$ & $-0,388$ & $<0,001$ \\
frango com pele & 0,116 & $-0,190$ & $-0,299$ & $-0,081$ & 0,001 \\
carne vermelha com gordura & 0,137 & $-0,232$ & $-0,344$ & $-0,119$ & $<0,001$ \\
peixe & 0,293 & 0,455 & 0,355 & 0,554 & $<0,001$ \\
feijão & 0,113 & $-0,348$ & $-0,553$ & $-0,142$ & 0,001 \\
\hline
\end{tabular}

* valores ponderados pelo número de adultos no domicílio do entrevistado, multiplicado pelo inverso do número de linhas telefônicas 